\title{
Facciones, linajes y conflictos urbanos en la Europa bajomedieval. Modelos y análisis a partir de Castilla y Toscana*
}

\author{
María Asenjo-González \\ Universidad Complutense de Madrid \\ Andrea Zorzi \\ Università di Firenze
}

RESUMEN: La conflictividad en los medios urbanos sigue siendo un tema de interés historiográfico de primer orden que en ocasiones se ha estudiado desde concepciones y apriorismos condicionantes, lo cual ha impedido conocer el desarrollo y el alcance de sus manifestaciones sociales, politicas, antropológicas y culturales. En las ciudades italianas el pretendido peso de los valores políticos heredados del mundo clásico y transferidos a la civilización occidental ha lastrado la percepción de su realidad histórica y en particular de una conflictividad, que encajaba mal con el compendio de las supuestas virtudes politicas del comune italiano. Para las ciudades castellanas el prisma de deformación sería el excesivo protagonismo político otorgado al poder monárquico y a su aparato institucional y normativo. Interpretación que se vio reforzada, en la década de los ochenta del siglo pasado, al conectarla con el origen del «estado moderno». Ese enfoque también ha limitado el estudio de la conflictividad urbana, en el marco de una sociedad política compleja, que también había gestionado el control de la violencia. Pero, tal y como se señala en el trabajo, el estudio de la conflictividad con menos condicionantes interpretativos puede arrojar mucha luz sobre cuestiones relevantes del funcionamiento social $y$ de la historia urbana.

* El presente trabajo recoge algunos resultados obtenidos en el transcurso del proyecto de investigación «La jerarquización urbana: villas y ciudades en Castilla (1400-1561)» Referencia HAR2010-15422 dirigido por la autora desde la U.C.M. financiados por el Ministerio de Economía y Competitividad (MINECO). Agradecemos a Ma Ángeles Martín Romera la ayuda prestada en la traducción del texto italiano. Abreviaturas: Archivo General de Simancas/ Registro General del Sello (AGS/RGS); Archivo General de Simancas/ Cámara de Castilla (Diversos). 


\section{PAlabras Clave: Ciudades; Italia; Toscana; Castilla; Baja Edad Me- dia; historiografía; conflictividad; bandos; linajes.}

Factions, lineages and urban conflicts in late medieval Europe. Models and approaches from Castile and Tuscany

ABSTRACT: Urban conflicts are a main historiographical field which study has been often conditioned by prejudices and misconceptions that prevented an appropriate knowledge of the development and consequences of their social, political, anthropological and cultural manifestations. In Italian cities, the so-called weigh of the political values from the Ancient world that would have been transferred to the Western civilization, has burdened our perception of the historical reality. Particularly regarding conflicts: an aspect that did not fit the ideal political virtues of the Italian comune. In the Castilian case, the main problem is the excessive political prominence attributed to royal power and its institutional and legal system, an approach that was reinforced in the 80's when it was linked to the origins of the "Modern State». These perspectives have limited the study of urban conflicts in a complex political society that also managed the control of violence. The article proves that, by putting aside some of the mentioned perspectives, it is possible to achieve new findings regarding conflicts, social behavior in urban history.

Key words: Cities; Italy; Tuscany; Castille; Late Middle Ages; Historiography; Conflicts; Factions; Lineages.

La normalización de la violencia ha sido una de las aportaciones más destacadas de la historiografía de la conflictividad, ya que considerar que la violencia es parte de la respuesta política e insertar su presencia ya sea en forma de conflictos, disensiones, enfrentamientos, rebeliones, agresiones, delincuencia, disciplinamiento y represión ha sido fundamental para situarla en parámetros de comprensión, que ayudan a estudiar a las sociedades del pasado y en alguna medida a conocer a la sociedad del presente ${ }^{1}$. El otro gran impulso lo aporta el creciente convencimiento de que la lógica de la política se expresa a través de un doble registro que en expresión anglosajona diferencia entre la política (politics) entendida en la ampulosidad del término asociado al discurso teórico de construcciones ideológicas y a la mecánica de las instituciones, y política (policy) centrado en las relaciones de poder y en la efectividad de recursos y estrategias para afianzarse en el mismo, en el marco de la vida cotidiana, y los modelos culturales, en los que se insertaban los grupos sociales y sus prácticas legítimas de acción ${ }^{2}$. Desde esta nueva óptica trataremos

1 ZORZI, 2002; 135. GAUVARD, 2005. GONTHIER, 1992. ACTES, 1989. BOONE, (Massachusetts, 2002). CABRERA, 1995.

2 ZORZI, 2008; 61-62. 
de profundizar en la gestión del conflicto y las lógicas internas de la acción de la violencia, en Castilla y Toscana, conscientes de que ello suponía saber gestionar la enemistad, utilizar las amistades y practicar el acuerdo, a fin de controlar y canalizar las emociones y las pasiones en contextos particulares de acción política e institucional. Asunto que requerirá también hacer un escrutinio acerca de los condicionantes historiográficos que han conducido la valoración de los acontecimientos de la violencia social y política en ambos territorios.

En el caso italiano, aunque el tema del conflicto constituye desde hace tiempo una de las cuestiones más tratadas por la historiografía internacional, en los estudios dedicados a las ciudades italianas se observa aún cierta confusión a la hora de afrontarlo, especialmente en lo que respecta a reconocer el alcance de dichas prácticas en la sociedad y en las formas de la política. Los intereses de la investigación se han centrado hasta años recientes en torno a otras cuestiones: en primer lugar, a conocer el perfil social de los grupos dirigentes de los «comuni» y el desarrollo de las culturas políticas. También ha prevalecido una interpretación de la experiencia comunal en un sentido marcadamente «público», dispuesta a indagar las formas de la participación política (y de la exclusión), el desarrollo de los consejos, la escritura de nuevas «normas», la afirmación de las funciones públicas en el campo judiciario y fiscal, la elaboración de una cultura y de una ideología política orientada al republicanismo, etc. ${ }^{3}$.

Dicha orientación parece expresar una cierta reacción respecto a las directrices que, en otros ámbitos espaciales y cronológicos, han mostrado una gran capacidad de renovar objetivos, métodos y perspectivas, apuntando a evidenciar la complejidad de las formaciones políticas, a analizar sus prácticas y lenguajes, no solo oficiales e institucionales, o a estudiar sus dimensiones informales y compuestas, entre las cuales se hallan precisamente las del conflicto. Cuestiones en las que las ciudades comunales italianas han sido consideradas durante mucho tiempo, como lugares en los que, después de muchos siglos, reemergió en Occidente la tradición antigua de la res publica, dando vida a realidades políticas y sociales que una prolongada línea de estudios ha interpretado, incluso en tiempos recientes, como la primera etapa de la afirmación del constitucionalismo, del parlamentarismo y del pensamiento político moderno europeos ${ }^{4}$.

El redescubrimiento de los valores de la edad clásica que tuvo lugar en los «comuni» italianos entre los siglos XII y XIV, ha sido interpretado como un elemento distintivo y peculiar de la ciudad y de la historia italiana, por parte de una venerable tradición de estudiosos. Basta recordar como ya hace dos siglos, entre Revolución y Restauración, un intelectual liberal como Simonde

3 Para más detalle ZORZI, (Boloña, 2008); 61-62.

4 Confirmar, por ejemplo, en ASCHERI, 2006a, PRATO, $2006 \mathrm{~b}$. 
de Sismondi les dedicó una monumental Histoire des républiques italiennes $d u$ moyen âge para subrayar la grandeza (incluso económica y social) de Italia, en la edad de los «comuni» libres frente a la sucesiva decadencia (también moral) en la época de los principados y de la Contrarreforma ${ }^{5}$. También en el ámbito de la tradición anglosajona la novedad y la importancia de las ideas y de las prácticas, que fueron elaboradas en las ciudades comunales italianas, han sido señaladas como el fundamento de la experiencia republicana después exportada a otros países, dando vida al paradigma, cultural y político, de la «Western civilization» ${ }^{6}$.

Los historiadores de las ciudades comunales han puesto de manifiesto cómo la política fue redescubriendo - primero a partir de la retórica ciceroniana y después del pensamiento aristotélico-, el arte de gobernar la ciudad con justicia, por la libertad de los ciudadanos y la paz de la comunidad, y de educar al buen gobernador, incluso a través de la elocuencia pública, en la persecución del bien común y en regir la ciudad para beneficio exclusivamente de sus ciudadanos ${ }^{7}$. Recientemente, ha aflorado de nuevo en algunos historiadores la tendencia a tildar explícitamente como «democrática» la experiencia política comunal $^{8}$.

Las ciudades comunales italianas han sido consideradas principalmente como incubadoras de experiencias públicas modernas, como etapas de la inicial «formación del Estado», en un contexto internacional de estudios que a su vez parece dispuesto a evidenciar la complejidad y variedad de las experiencias sociales y políticas del pasado. Siguiendo con los temas del conflicto en época medieval, piénsese, por ejemplo, en la reciente relectura de los sistemas de venganza en el Occidente altomedieval, que han evidenciado sus componentes racionales con una alternancia calculada entre violencia y reconciliaciones, de estrategia y justificaciones de construcción narrativa ${ }^{9}$; en los resultados de las investigaciones dedicadas a las sociedades señoriles, antes y después de la mutación «feudal», que han mostrado la estrecha interacción de las prácticas conflictivas y de las estrategias de pacificación con la acción de los grupos sociales y de los núcleos de dominio, probando el hecho de que son parte integrante de la esfera política ${ }^{10}$; o en los estudios sobre los estados territoriales italianos que han enriquecido la dimensión de estos aspec-

5 Ver el replanteamiento en traducción italiana: SIMONDE DE SISMONDI, 1996.

6 Es obligado citar a: POCOCK, 1975. SKINNER, 1978. BOCK, SKINNER, y VIROLI, 1990. SKINNER y VAN GELDEREN, 2002.

7 Ver, por ejemplo, MUNDY, (Massachusetts, 1989) y ARTIFONI, (Prato, 1994); 2000, 2004.

8 En los trabajo de ASCHERI, 2006a, (Prato, 2006b), ARTIFONI, (Prato, 1994); 2000, 2004 y MILANI, (Prato, 2006).

9 BARTHELEMY, BOUGARD y LE JAN, 2006.

10 BOSSY, 1983. HEAD y LANDES, 1992. ATTI, 1997. BROWN y GÓRECKI, 2003. 
tos, analizando el papel de las parentelas, la formulación idiomática de las faidas o venganzas, la perduración de las facciones, la cultura del honor, etc. ${ }^{11}$.

El panorama de las investigaciones es hoy en día vastísimo y se mantiene en continua evolución, pero para limitarnos al ámbito urbano bajomedieval se pueden recordar los importantes estudios realizados por Daniel Lord Smail sobre la práctica de la vendetta por vía judicial en Marsella ${ }^{12}$, por Wim Blockmans y otros sobre las venganzas nobiliarias en las ciudades flamencas $^{13}$, por Barbara Frenz sobre la paz y los procesos penales en las ciudades alemanas $^{14}$, por varios estudiosos sobre las prácticas de solución de los conflictos y sobre las de venganza en las sociedades castellanoleonesas y sobre las facciones políticas en las ciudades de la España bajomedieval ${ }^{15}$. Todos estos ejemplos confirman un interés generalizado y duradero por estos temas en la historiografía internacional ${ }^{16}$.

\section{2.}

La lenta consolidación del interés por el tema de los conflictos en las ciudades comunales italianas ${ }^{17}$ ha estado condicionada probablemente por las directrices de investigación abiertas en los años setenta del siglo pasado sobre temas cercanos a Jacques Heers y Lauro Martines. El primero fijó su atención en el «clan» familiar y sus «partidos» como estructuras sociales y políticas en el Occidente medieval, centrándose especialmente en las fuentes italianas, sobre todo cronísticas, y evidenciando las formas de la violencia, de la vendetta y de la pacificación ${ }^{18}$. El segundo recogió una serie de artículos de diferentes autores sobre la «violencia y el desorden cívico» en las ciudades italianas, durante el largo periodo bajomedieval ${ }^{19}$. El escepticismo con el que fueron acogidos por medievalistas italianos las contribuciones de Heers, al que se le acusó de un enfoque esquemático y «antropologizante» ${ }^{20}$, y la generalidad de la noción de violencia elegida por Martines, contribuyeron a enfriar el interés por estos temas.

11 RAGGIO, 1990. MUIR, 1993. CONNELL, 2000. DELLA MISERICORDIA, 2000. CAVINA, 2001, GENTILE, 2005.

12 SMAIL, (Oxford, 1996); 2003.

13 BLOCKMANS, 1987; 1990. BUYLAERT, (Amsterdam, 2007).

14 FRENZ, 2000; 2003.

15 SABATÉ, 1995; (Valencia, 1998). ASENJO-GONZÁLEZ, 2013.

16 CARROL, 2006: 1-25. NETTERSTRÖM, 2007.

17 ZORZI, 2009:7-41.

18 HEERS, 1974; 1977.

19 MARTINES, 1972; (London, 1968).

20 TABACCO, (Spoletto,1976). 
En una serie de contribuciones posteriores, aparecidas a la mitad de los años noventa, Andrea Zorzi ha intentado replantearlo, ligándolo al discurso historiográfico ya existente para otras sociedades del pasado, con el objetivo de evidenciar la normalidad de las relaciones sociales conflictivas, la pluralidad de las formas de conducción y de resolución (pacífica, violenta y sancionadora) de los conflictos, la gran difusión social de las prácticas de faida, y la legitimación y la centralidad de la cultura de la vendetta en la sociedad política comunal. Refiriéndose también de forma dialéctica a algunos de estos artículos, Jean-Claude Maire Vigueur ha dedicado un par de extensos párrafos a la «cultura del odio» y a los modos y formas de conflicto en su monografía sobre la militia urbana $^{21}$, señalando en los conflictos violentos entre los linajes uno de los aspectos más típicos del estilo de vida y el sistema de valores de la nobleza urbana, reconduciendo así estas prácticas como un atributo de la clase caballeresca y midiendo sus confines cronológicos y sociales, que serían sustancialmente ajenos a los grupos y experiencias del «popolo» ${ }^{22}$. Pasando de la inicial atención por las disputas sobre la posesión fundiaria en la Italia lombarda y carolingia, y extendiendo las investigaciones a la Toscana del siglo XII, también Chris Wickham ha demostrado la centralidad de los conflictos en las prácticas sociales de la edad protocomunal y su naturaleza interclasista, subrayando la estrecha interacción de los modos arbitrales de resolución con la acción de las primeras instituciones comunales (colegios consulares) y con la flexible variedad de instrumentos jurídicos ${ }^{23}$. Los resultados de estos estudios, que comienzan a definir algunas líneas de la evolución y de la diferenciación de las prácticas del conflicto sobre la larga andadura comunal entre los siglos XII y XIV, han sido recibidos como elementos de novedad y de revisión de la historiografía comunal desde las síntesis más actualizadas, que han sido dedicadas en los últimos años a las ciudades comunales italianas ${ }^{24}$.

Paralelamente se ha ido desarrollando también un filón de estudio sobre el tema de la paz en las sociedades urbanas bajomedievales; una categoría que, a la par que aquella de la violencia, parece tan omnipresente en las sociedades históricas en cuanto es genérica, o «polisémica» ${ }^{25}$. El tema ha sido desarrollado en varias direcciones: como aspecto especular de la guerra, como instrumento de disciplinamiento de la sociedad, como objeto de predicación, como

21 MAIRE VIGUEUR, 2003; 307-335.

22 Sobre la vendetta entendida como competencia magnaticia: LANSING, 164 y ss. y 184 y ss. KLAPISCH-ZUBER, 2006; 109-142.

23 WICKHAM, (Roma, 1996): 7-93; 2000.

${ }^{24}$ CROUZET-PAVAN, 2001: 121-162; MENANT, $2004:$ 49-52, 63-65; 2005 : 89-94, 103-107; BOUCHERON, 2004, 27-31, 61-62, 144-149.

25 Como destaca ROSSI, (Verona, 2005): 9-46. 
instituto/fundamento jurídico e instrumento procesal, etc. ${ }^{26}$. En estos estudios ha prevalecido el recurso a las fuentes doctrinales, en primer lugar a la tratadística teológica y política, a la homilética, ya que en gran medida los estudiosos que se han ocupado de esto provienen de carreras investigadoras centradas en la elaboración intelectual y en las representaciones culturales, religiosas y jurídicas. Esto contribuye también a explicar por qué han sido hasta ahora pocos, y limitados a los comunes italianos, los trabajos dedicados a las paces como método de solución de los conflictos entre individuos y grupos familiares, a aquellas que, no sin cierta simplicidad, han sido llamadas en general «paces privadas» ${ }^{27}$, y que tienen como referencia documental privilegiadas fuentes de aplicación como las actas notariales y las deliberaciones de los consejos ${ }^{28}$.

El dato más relevante que emerge de estos estudios es la dificultad o el desinterés por mantener unidos los dos ámbitos de análisis. La atención por las prácticas de pacificación excede de hecho aquella, por las causas y por las formas del conflicto: al contrario, a menudo el momento de la paz se presenta como contraposición al del conflicto. El resultado es una especie de división entre dos prácticas que por el contrario estaban estrechamente interconectadas y constituían un proceso continuo entre elementos presentes en las estrategias de confrontación, como ya había mostrado Max Gluckman desde $1955^{29}$.

\section{3.}

La lenta gestación de un nuevo interés por el tema de las facciones y de los conflictos explica también por qué en la común visión historiográfica ha prevalecido hasta tiempos muy recientes una «narración» de la vendetta en la sociedad comunal, que describe en términos negativos la violencia que la atravesaba como un estado de caos endémico, como un dato estructural de larga duración, alimentado por los comportamientos y por los estilos de vida de una inquieta aristocracia caballeresca, que acompañaron de modo turbulento y desestabilizante del discurrir político comunal, desde sus inicios consulares hasta los epílogos de soluciones señoriles y oligárquicas. En reacción a esto, también los grupos sociales «populares» debieron asociarse pronto en milicias y practicar la violencia armada para garantizar el control de los propios miembros y para afirmarse en el plano político. La violencia de la socie-

26 Respectivamente, DESSI, 2005; 245-278. MICHETTI, 2005; 279-312. BÉRIOU, 2005; 357-366. IANNELLA, 2005; 367-382. VALLERANI, (Roma, 1999): 315-354.

27 Por ejemplo: SENSI, (Verona, 2005): 159-200. ROVIGO, (Verona, 2005): 201-233.

28 ZORZI, 2009; 2010; 265-301.

29 GLUCKMAN, (Oxford, 1955). Recientemente ha sido retomado por CARROLL, (Oxford, 2003). 
dad comunal se originó de hecho, principalmente, por la dificultad de disciplinar los modelos de vida y los sistemas de valores de los linajes aristocráticos (los milites, los potentes y después los magnates).

Desde esta óptica, la vendetta es considerada el emblema de la violencia de las grandes familias, el aspecto peculiar que habría caracterizado sus prácticas de tutela del honor y de afirmación de la superioridad social: la vendetta como atributo eminentemente aristocrático, como estilo de vida enraizado en el ethos caballeresco. El espíritu de vendetta habría alimentado el estado de violencia cotidiana del que hablan las crónicas urbanas. De esa forma, la afirmación del comune habría llevado consigo la instancia racional del disciplinamiento de la violencia, promovido sobre todo por los grupos sociales que, ligados a la producción y al comercio, se presuponen portadores de sistemas de valores funcionalmente orientados al orden público, a la seguridad y a la tranquilidad civil. Como característica peculiar, estos valores se habrían nutrido de palabras de orden como «paz», «concordia», «justicia», «bien común», etc., el programa político de los regímenes del «popolo» y las relativas prácticas de propaganda y comunicación simbólica.

La fuerza de las instituciones comunales, que en algunos estudios es indicada de forma weberiana, en la reivindicación del monopolio público de la violencia, habría desplegado por lo tanto también una serie de medidas dirigidas a vetar la vendetta y, consecuentemente, el comportamiento faccioso. Sobre todo, habría sido la afirmación de la justicia pública, centrada en el proceso, sobre las investigaciones ex officio y sobre la pena, la que habría ido sustituyendo progresivamente las formas «privadas» de justicia, animadas, a su vez, por la espiral del desagravio. La persistencia en el tiempo, aún bien entrados los siglos XIV y XV, de estas actitudes violentas, que en más de un historiador parecen asociadas a las prácticas brutales de la faida, se encuadra, en su mayor parte, en el paradigma de la «decadencia» de la vendetta: una persistencia de prácticas anacrónicas y toleradas en espera de ser inexorablemente erradicadas por la acción del Estado.

Por otra parte, se puede observar una contradicción intrínseca en este tipo de «narración»: por un lado, se expresa la convicción de que el afianzamiento del comune como gobierno público habría marginado progresivamente las prácticas de la vendetta; por otra parte, estas son a su vez interpretadas, recalcando de hecho la representación de los cronistas contemporáneos, como la causa de la crisis del orden comunal y de la afirmación de los poderes señoriles. El punto crítico parece ser la dificultad de percibir, no solo lo usual de las prácticas vengativas sino, sobretodo, su relación estrecha con la dimensión de la política. En otras palabras, persiste aún la idea de que la vendetta constituye una dimensión antisocial y anti-estatal de la vida civil.

Por contra, la lógica de la vendetta era en todo caso la limitación de la violencia surgida. Esta actuó a favor del equilibrio de las relaciones entre las 
partes en conflicto y fue un mecanismo potente de integración social, para la búsqueda de mediadores, de árbitros y de soluciones que, alcanzada la reciprocidad entre las ofensas, garantizaran una pacificación ${ }^{30}$. La naturaleza ordinaria de la vendetta como relación social emerge entonces como un dato estructural, difícil de atribuir como actitud peculiar de un grupo social predeterminado, empezando por el caballeresco, ya que la opción de vengarse por las ofensas recibidas y, sobre todo, de conducir a lo largo del tiempo un conflicto en términos de faida, eran iniciativas que los individuos y los grupos de parentelas ponderaban en función de la disponibilidad de los recursos adecuados, independientemente del status social. Esto explica también por qué recurrían a ellas con mayor facilidad las familias y linajes más poderosos, sin ni siquiera reivindicarlo como una prerrogativa de tipo grupal.

No menos importante es el contexto consensual que emerge en muchos estudios y que legitima las prácticas de la vendetta en el plano social, jurídico y cultural. Esto explica por qué en muchas sociedades, incluida la comunal, esta representaba una dimensión activa de la política, era objeto de la educación política y podría desempeñar un papel lingüístico en la reivindicación de la identidad de los actores políticos. La vendetta expresa de hecho un lenguaje con fuertes connotaciones «performativas», como se suele decir hoy: actos de reivindicación, tutela del honor, solicitud de vínculos de pertenencia, etc.

Se puede observar además como también entre los estudiosos, que recientemente han reconocido la difusión de las prácticas y de la cultura de la vendetta en la sociedad comunal, no pocos prefieren continuar afirmando y reiterando una visión sustancialmente negativa, subrayar la acción reguladora a la que fue sometida, evidenciar la constante tensión entre ímpetus de paz de la que fue objeto, o enfatizar la preminencia de la justicia pública en la reglamentación de los conflictos. Reiterando, en definitiva, la íntima convicción de que se trate siempre de prácticas marginales y sustancialmente residuales de la acción política, respecto, por ejemplo, a la participación en los oficios de la res publica, a la afirmación de los consejos cuyo lugar se considera central en la actividad política comunal, o al conflicto entre las partes (güelfa y gibelina), porque son más formalizadas y aparentemente reconocibles ${ }^{31}$. Se trata de opciones fuertes, netas ideológicamente (donde se vuelve a subrayar, más en general, la naturaleza «democrática» del republicanismo comunal), que en algunos intérpretes parece no admitir dudas. Esta vía corre el riesgo de renunciar a matizar y enriquecer y, por lo tanto — quizás - también a comprender mejor, el análisis de los modos y formas de la política en la sociedad comu-

30 Sobre el arbitraje en las ciudades medievales italianas: KUEHN, 1991: 19-74, 259266, 271-288. WICKHAM, 2000: 28-30, 70-71. MENZINGER, 2006: 113-134.

31 MILANI, 2005. 
nal, que fueron más plurales y complejos de cuanto hasta ahora muestran sus reconstrucciones.

4.

La conflictividad en las urbes castellanas se instala en otro paradigma histórico ya que aunque gozaban de una gran capacidad política de autogobierno, jurisdicción, defensa y fiscalidad, las ciudades se encontraban sujetas a la obediencia al rey y colaboraban en la gestión de las competencias fiscales, jurídicas y militares en su distrito urbano y territorial. Desde principios del siglo XIX, el marco institucional de gestión política urbana se ha visto desenfocado historiográficamente por la interpretación de los institucionalistas, que realzaron el protagonismo de la intervención regia y en el curso de los años noventa se reelaboró esa relación desde la perspectiva de los «orígenes del Estado moderno ${ }^{32}$. Así, la ciudad se mostraba perfectamente conectada a los intereses de gobierno de la monarquía y se reconocía en las afinidades que destacaban teóricos políticos como Rodrígo Sánches de Árevalo y Eiximenis para la comunidad, extrapolando el sentido de la civitas según los usos dados a la misma por Aristóteles ${ }^{33}$. Un enfoque que necesariamente sobredimensionaba la capacidad y los recursos de la monarquía, sitúa el análisis histórico en un continuum historiográfico de perfil teleológico que oculta problemas, deforma y desvirtua la capacidad del poder monárquico ${ }^{34}$. Esa sobrevaloración ha condicionado también la percepción de la conflictividad para considerarla únicamente como una anomalía, que se reconduciría gracias a la intervención del rey y para beneficio del reino. Desde una perspectiva distinta y de mayor interés por la lucha social J. Valdeón interpretaba que la conflictividad entre 1351 y 1521 habría surgido como resistencia a la construcción del naciente «estado moderno» y a la centralización ${ }^{35}$, y los movimientos de resistencia popular habrían potenciado el papel arbitral de la monarquía, en el conjunto de la sociedad política de la que el rey era instancia suprema, tanto para la búsqueda de la concordia como para la reparación de agravios ${ }^{36}$. Pero ni siquiera la

32 RUCQUOI, 1987; 1991. LADERO QUESADA, 1997. VALDEÓN BARUQUE, 1997. ASENJO-GONZÁLEZ, (Madrid, 1990); (Madrid, 2005); 2013.

33 SÁNCHEZ DE ARÉVALO, 1959:39. ANTELO IGLESIAS, (Madrid, 1985). CERVERA VERA, 1989.

34 Algunos autores han destacado que la relación armónica ciudad-Estado no cubre todos los aspectos que se le atribuyen LÓPEZ GÓMEZ, 2008:21.

35 VALDEON BARUQUE, 1997: 502.

36 Por lo que los recursos a la actuación de la justicia reforzaban la institución monárquica y fortalecían el «Estado moderno» VALDEON BARUQUE, 1997: 511, 513. 
conflictividad política desaparecería en los inicios de la modernidad, ante la llegada de formas autoritarias de poder monárquico ${ }^{37}$.

La otra característica urbana es la composición hidalga, caballeresca y militar de su oligarquía y de los regidores del concejo castellano, aspecto que situará las ocasiones de violencia en un marco conflictivo marcado por la impronta de la incipiente recepción de los códigos de caballería y también su conexión con el mundo de valores de la nobleza dominante, en particular en núcleos de importancia como Toledo, Murcia y la mayoría de las ciudades andaluzas ${ }^{38}$. Hubo un comportamiento emulado por mercaderes, élites de artesanos y oficiales regios, que no dudaban en reproducir sus patrones de comportamiento y actitudes sociales en diferentes ocasiones y circunstancias de la vida social y política que agrandaban su presencia.

Por la normativa foral y la documentación, sabemos que parte de la gestión de la violencia se hacía con la firme colaboración de la primera sociedad concejil y su intervención pacífica, violenta o sancionadora parecía ser la clave de las soluciones propuestas. En esas disposiciones el concejo apenas intervenía salvo para asegurar la aplicación del fuero ${ }^{39}$. En el curso del siglo XIII se evidencian enfrentamientos entre caballeros y hombres buenos, a partir de la rivalidad surgida por el dominio del territorio, la gestión de los recursos y del poder político. Esa rivalidad dio origen a la aparición de los linajes urbanos y también abrió brechas en la cohesión urbana para la gestión de la conflictividad, dando opciones en aumento a la intervención de poderes arbitrales como los de la justicia y la legislación regias ${ }^{40}$. El poder monárquico, que inicialmente actuaba como árbitro, fue ganando relevancia de facto, argumental y política, ante el vacío de la gestión de la justicia foral por la grave carencia de consenso social para abordar dicha tarea, y el recurso a los tribunales y a las leyes del rey se fue haciendo creciente ${ }^{41}$. De forma simultánea, a partir del siglo XIII un sector de los poderes urbanos aparece articulado en linajes de caballeros, que agrupaban a las facciones de milites en organizaciones poco

37 Las luchas de bandos se mantuvieron en el País Vasco y en ciudades andaluzas como Úbeda y Baeza: SORIA MESA, 2007. HERRANZ TORRES, 2010: 27-94.

38 Un perfil de comportamiento caballeresco que se ajustaba a la naturaleza de sus patrimonios y fortunas, basados en las actividades agropecuarias, con predominio ganadero, que no desplegaban relaciones de dependencia vasallática sobre la propiedad, uso y explotación de la tierra. MARTIN CEA y BONACHIA HERNANDO, (Valencia, 1999). MENJOT, 1991.

39 ALFONSO ANTÓN, 2005; 2006; ASENJO-GONZÁLEZ, 2011.

40 Todavía a mediados del sigo XIV las disputas conectaban con las rivalidades entre caballeros/regidores y hombres buenos/común sobre la gestión del gobierno, motivos familiares e intereses particulares: BONACHÍA HERNANDO, 1997; 1089.

41 La intervención regia también fue aprovechada en la opción legislativa, en particular durante los reinados de Fernando III (1217-1252) y Alfonso X (1252-1284) que trataron de tomar iniciativas de homologación y difusión del derecho común en el ámbito concejil: GONZÁLEZ JIMÉNEZ, 2004. MARTÍNEZ DIEZ, 1993. 
jerarquizadas bajo modelos familiares y clientelares, llamados a liderar los conflictos e intervenir en luchas por el poder con los hombres buenos (boni homines), organizados éstos de modo similar y asegurados en el común urbano y en la defensa de fueros y privilegios ${ }^{42}$. El protagonismo creciente de la mediación se vio animado por la lucha por el poder político que derivaba en rivalidades y tensiones surgidas por diferentes motivos ${ }^{43}$.

Pero con frecuencia la documentación menciona la conflictividad política asociada a una serie de acciones delictivas interpretadas como resultado de inoperancia de la contención de la justicia local ${ }^{44}$. Unas acciones que no separan lo público de lo privado y, aunque no siempre estuvieron conectados a la rivalidad por el control del poder urbano, cabe suponer que así fuese, dada la imbricación de la política en la acción privada de las gestiones de gobierno. La solución de esas diferencias y disputas habitualmente requerían de la capacidad de acuerdo y contención que cabe encontrar en sociedades jerarquizadas como eran las de los medios urbanos de Castilla ${ }^{45}$.

La estructura reticular de las clientelas urbanas favorecía que los conflictos derivasen en luchas políticas que afectaban a la seguridad y al orden público, creando desconcierto y favoreciendo las acciones de la delincuencia, cuya prevención y reducción, en las ciudades castellanas, era responsabilidad de los vecinos de la ciudad ${ }^{46}$. Ese marco de convivencia de las sociedades urbanas de la baja edad media era el que correspondía a formaciones sociales complejas, que se veían obligadas a convivir en reducidos recintos y a compartir infraestructuras y medios, que mantenía en común y soportaban por sus propios medios. Una conflictividad que estaba latente si bien se hacía perceptible en momentos puntuales, que obligaban a poner a prueba todos los recursos para sofocar y reducir sus acciones y consecuencias. Con frecuencia, las formas menores de conflictividad no pasarían de enfrentamientos puntuales, y que fueran a más o que quedaran reducidas dependería del alcance y la fuerza de los beligerantes. En esos casos, la sociedad urbana, al estar articulada y jerarquizada, podía poner en acción mecanismos de cierre, opresión y control

42 Todavía en Burgos en 1411 y 1426 se pueden seguir las consecuencias de enfrentamiento entre los regidores y los hombres buenos en los asuntos justicia y política del concejo. La redacción de unas ordenanzas de justicia y el acuerdo del Conde de Aranda surgen tras episodios de tensión urbana en las que se opta por la salida hacia la regulación de la justicia y la regulación de las representaciones políticas del concejo. BONACHIA HERNANDO, 1978; 164-68. ASENJO-GONZÁLEZ, 2006.

43 ASENJO-GONZÁLEZ, (Vitoria, 2009a).

44 BONACHÍA HERNANDO, 1997. 1085-86.

45 ASENJO-GONZÁLEZ, 2008; 2013.

46 Cuando los enfrentamientos políticos derivaban en amenazas y violencia había temores y los vecinos encargados de la defensa del orden público se negaban a acudir poniendo en peligro la organización policial urbana: LÓPEZ GÓMEZ, 2006b: 68. 
con la intervención de linajes y bandos, que pretendían ser disuasorios antes de que los sucesos derivasen en conflictos abiertos ${ }^{47}$.

En algunas ciudades la rivalidad estructural de linajes y bandos estaba firmemente arraigada y condicionaba la vida política que, a su vez, se construía sobre relaciones sociales de todo tipo: familiares, clientelares, de dependencia, profesionales, religiosos y demás posibles opciones. Así, familias, bandos, facciones y linajes coincidían en ser opciones de encuadre y agrupación social, proclives a las manifestaciones de violencia en las que apreciamos algunas diferencias entre si. En ese sentido, las facciones y los bandos serían el marco más versátil de agrupamiento, mientras el linaje iba conectado a formas estructuradas y perdurables de encuadre, al combinar aspectos profesionales (militares), familiares y de fuerte cohesión horizontal para los caballeros urbanos, que se irían adaptando según ámbitos regionales y ciudades ${ }^{48}$. Al ser bandos y facciones grupos de encuadre menos definidos en su estructura eran también más inestables en su tamaño y perduración de su fuerza combativa. A veces permanecían cuando la lucha por el poder político se había apaciguado y se mantenían expectantes en el ámbito local, pero si la lucha era de alto nivel, en el ámbito regional o de todo el reino, entonces podríamos hablar de partidos ${ }^{49}$. Generalmente para la acción de estas formaciones políticas se requerían circunstancias de convivencia, participación conjunta y colaboración previas, que más tarde derivarían en afinidades duraderas ${ }^{50}$. Por lo tanto, cabe pensar que si los linajes y los bandos canalizaban adhesiones más consolidadas, y se instalaban en una rivalidad conocida y prestablecida, las facciones o partidos se acomodaban mejor a las presiones o intereses de poderes locales o foráneos, que concitaban e implicaban a los vecinos para actuar con apoyos internos y hacer de la ciudad el escenario en el que resolverían sus rivalidades.

En el siglo XV los bandos conectaban luchas políticas que concernían a todo el reino, pero también disputaban en las ciudades por asuntos diversos y de menor entidad, que muestran el perfil más cotidiano de la rivalidad entre

47 MACKAY, 1985.

48 El término linaje es una denominación equívoca que requiere matices y precisiones. Sobre los linajes en Castilla contamos con abundante bibliografía que permite matizar el significado de un término utilizado con diferentes propósitos y en distintos espacios al estar adecuado a realidades sociales muy diferentes. La simple idea de conectarlo a la forma familiar de estructura cognaticia no resuelve la variedad de acepciones y significados que ofrece desde mediados del siglo XIII. ASENJO-GONZÁLEZ, (Barcelona, 2009b). MONSALVO, 2013.

49 De ese modo, los partidos podrían agrupar a diferentes facciones, que en ocasiones habrían podido existir anteriormente, sin perder su identidad. Ver BRAAKE, (Cambridge, 2009): 90 .

50 BRAAKE, (Cambridge, 2009):109. 
miembros de esas facciones ${ }^{51}$. La participación de la nobleza en esas luchas se hizo más frecuente en el siglo XV y, en las ciudades más septentrionales, se aprecia una circunstancia singular de acercamiento del territorio y la sociedad rural a la ciudad con la creciente influencia de los llamados «parientes mayores» en la política de las villas vascas ${ }^{52}$. Las villas del Cantábrico, y de los señoríos de Vizcaya y Guipúzcoa sufrieron una conflictividad prolongada en el siglo XV y principios del XVI, y sabemos que, a pesar de los esfuerzos y la intervención de los oficiales regios, no se lograría reducir hasta bien entrado el siglo XVI ${ }^{53}$. Una violencia que se trataba de solucionar recurriendo a medidas de contención que suponían: la distribución acordada de cargos y oficios, aprobación de ordenanzas de gobierno y justicia, la mediación de las hermandades, que gestionaban y resolvían problemas de violencia y de orden público en el territorio, y finalmente la intervención de los enviados reales, merinos y corregidores principalmente, con poderes y competencias para actuar puntualmente en cada caso ${ }^{54}$.

En general, el desarrollo de la violencia de bandos y parcialidades fue más acusado en los siglos XIV y XV, y es de común aceptación que a partir del reinado de los Reyes Católicos hubo una aminoración de esas formas violentas, gracias a la acción de los reyes, que enviaron corregidores y justicias reales, al tiempo que introducían cambios de gobierno, otorgaban nuevas competencias a los grupos oligárquicos y compensaban con la adquisición de juros a los poderes emergentes de las sociedades urbanas ${ }^{55}$. Pero el efecto pacificador de los reyes sabemos que fue desigual en las distintas ciudades y reinos, y en algunos ámbitos se tardó mucho tiempo en lograr un estatus de equilibrio, a causa de las disputas banderizas ${ }^{56}$. La desestabilización provocada por la vio-

51 Episodios de violencia que se describen en Toledo o en otras ciudades de Castilla o Andalucía: LÓPEZ GÓMEZ, 2006b, 2008. CABRERA MUÑOZ, 1995.

52 GARCÍA FERNÁNDEZ, 2013.

53 La violencia banderiza en los territorios vascos se polarizó en los enfrentamientos entre Oñacinos y Gamboínos que mantuvieron luchas que pasaron del mundo rural al ámbito urbano: DÍAZ DE DURANA ORTIZ DE URBINA, 2001. TENA GARCÍA, (Salamanca, 1990), 156.

54 DÍAZ DE DURANA ORTIZ DE URBINA, 2001; DÍAZ DE DURANA ORTIZ DE URBINA y FERNÁNDEZ DE LARREA, 2013.

55 ASENJO-GONZÁLEZ, (Barcelona, 2009b).

56 A través de la documentación conservada en el Archivo General de Simancas, las denuncias de acción de los bandos entre 1476-1492 se refieren sobre todo a villas del Cantábrico y País Vasco. Con menor incidencia figuran otras ciudades de Andalucía o Castilla. Son 38 de los 49 documentos en el Registro General del Sello. Denuncias de acción de los bandos: Archivo General de Simancas/Registro General del Sello: RGS, legajo,149101,42; RGS, legajo,149407,237; RGS, legajo 149404,242; RGS, legajo149404 383, RGS, legajo 148402,70; RGS, legajo 149204,293; RGS, legajo 149304,136; RGS, legajo 149603,142; RGS, legajo 147809,56; RGS, legajo 148010,114; RGS, legajo 149007,111; RGS, legajo 149007,213; 
lencia de la lucha entre parientes mayores y villas, en los territorios de los señoríos de Vizcaya y Guipúzcoa, fue aprovechada por la monarquía ${ }^{57}$ para hacer avanzar el control regio en esos territorios, siempre exhibiendo argumentos de «defensa de la patria» y el «pro del bien común» ${ }^{58}$. Pero sin duda, las ordenanzas de prohibición de bandos y elección de oficios acabarían con la praxis de buscar soluciones de acuerdo, al introducir la insaculación como sistema de designación de los cargos del gobierno ${ }^{59}$.

La intervención de la justicia regia reconducía conflictos pero no aseguraba plenamente la desaparición de la violencia, que se seguía manteniendo en el juego cotidiano de equilibrios entre fuerzas y relaciones de poder. En esos casos, sus intervenciones actuaban sólo si fallaban los recursos de contención y se solicitaba la acción del juez pacificador, corregidor, que recondujese la situación al inestable equilibrio de la convivencia.

En cuanto a las cronologías de la conflictividad responden también a los grandes acontecimientos de inestabilidad que vivió el reino, que obviamente repercutían en la firmeza de los poderes locales, que acababan siendo arrastrados hacia enfrentamientos movidos como correa de transmisión ${ }^{60}$. Aunque el germen del conflicto era local, lo mismo que sus agentes y actores, lo único que cambiaba era el estímulo que ofrecía la ocasión de manifestar la discordia, que podía llegar asociado a diferentes apariencias y en distintos momentos. No obstante, es una cuestión conocida que se podrían aportar detalles acerca de la regularidad más o menos establecida y relacionada incluso con la

RGS, legajo 147908,28; RGS, legajo 149507,252; RGS, legajo 149307,218; RGS, legajo 148403,224; RGS, legajo 148402,95; RGS, legajo 148406,77; RGS, legajo 148507,0; RGS, legajo 148411,77; RGS, legajo 148508,35; RGS, legajo 149309,46; RGS, legajo 149402,186; RGS, legajo 149810,236; RGS, legajo 149702,145; RGS, legajo 148902,308; RGS, legajo 149411,416; RGS, legajo 149311,42.

57 Allí, las luchas se imbricaban en rivalidades y diferencias sociales, económicas y políticas e iban asociadas a la intervención de los llamados «parientes mayores»: AGS/RGS legajo1484-11, 77, $\mathrm{f}^{\mathrm{o}} 1 \mathrm{v} /$ / $A$ esto vos respondo que en vos aver quitado e partido e quitar e partir e quitar(sic) de los linajes e parcialidades e vandos e aver fecho sobrello lo que agora fesistes avedes fecho bien, e lo que de al ys e lo que buenos e leales naturales deven faser por el bien común de su patria, e vos lo tenemos en servicio e vos otorgamos e concedemos todo lo contenido en este (capitulo) como nos lo suplicades e ordenamos e mandamos»,

58 Se incluía también esa mención en el juramento obligado de los oficiales elegidos hecho ante el altar y unido a la voluntad de «guardar el servicio de Dios e de vuestras e de vuestras (sic) altesas e el pro e bien común de la dicha villa e su tierra». Pero el concepto del «bien común» a fines de la Edad Media, debe de ser entendido desde una óptica adecuada al tiempo en el que se aplicaba, ya que entonces era utilizado frecuentemente en favor del afianzamiento de poderes superiores como la soberanía regia. Ver GAMBERINI y ZORZI, 2011: 10-11.

59 GARCÍA FERNÁNDEZ, 2013: 78 y ss.

60 Las ocasiones de enfrentamiento se prolongan en los reinados de los Reyes Católicos y trascienden el siglo XVI, Con particular énfasis en los momentos de cambio dinástico o de reinado, como 1474, 1506 o 1516. 
ritualidad de los enfrentamientos, las ocasiones, períodos o frecuencias de acciones violentas. Así, los tiempos de conflicto más repetidos solían coincidir con las fiestas señeras, que eran momentos en los que se procedía también a la elección de los oficios de los concejos ${ }^{61}$. Las prohibiciones de enfrentamientos en la misa del domingo, la celebración de vísperas y de fiestas como san Miguel o san Juan, convocatorias que se aprovechaban para resolver asuntos de elección de cargos y acciones de justicia, denotan que, sin temor de prohibiciones eclesiásticas, en esos días podrían surgir conflictos y violencia con armas $^{62}$.

Pero sin duda, era la nominación o elección de los cargos concejiles la ocasión más frecuente enfrentamiento. Sólo los acuerdos que dejaban pactados los repartos de cargos evitaban enfrentamientos, ya que la pugna por los oficios del concejo, de cualquier rango, constituía causa de posible conflicto puesto que representaba la conexión con el poder, que daba cohesión al grupo oligárquico, visualizaba su fuerza y su capacidad y ponía a prueba su potencia y habilidad en la lucha por conseguirlo. Para evitar conflictos la solución de acordar repartos entre los bandos-linajes era la mejor opción ${ }^{63}$. Una vez aceptada esa partición, se disponía la adscripción de los caballeros con opciones, ya que era una forma de estructurar administrativamente el grupo. Los linajes de caballeros aspiraban al equilibrio, articulando e inscribiendo a sus miembros, en los que se conoce en Ciudad Rodrigo y en Salamanca como matrículas de los linajes o inscripciones formales de todos aquellos caballeros que aspiraban a tener un oficio menor ${ }^{64}$. De ese modo se ponían en práctica la eficacia del reparto articulado del poder en el seno de cada bando. Las ventajas del procedimiento eran afianzar las aspiraciones individuales, dentro de cada grupo, al tiempo que se evitaba la monopolización, acaparamiento y privatización de los cargos y oficios.

Al parecer, también pudo ser definitiva la introducción de nuevos modelos de gobierno y de gestión, que exigían formación y alfabetización para el ejercicio de la política ${ }^{65}$. Aunque en las villas guipuzcoanas, esa exigencia, al principio, pretendía dejar fuera a los parientes mayores para acceder a esos

61 SOLÓRZANO TELECHEA, (Barcelona, 2005).

62 AGS/RGS legajo 1498-05, f 1 - 2r. Confirmación de ciertas ordenanzas que se insertan -su fecha: 22 de abril de 1498- que en la ciudad Úbeda y en la de Baeza fueron hechas por su corregidor, Pedro Gómez de Setúbal, para evitar los bandos y parcialidades. En esas ordenanzas se prohíbe a los escuderos ayudar con armas o sin ellas a los caballeros en ruidos y bandos, no acompañarles en misa o en fiestas, ni vísperas, ni en otras ocasiones.

63 En Ciudad Rodrigo, en 1414 se establecieron las reglas del reparto de cargos entre los linajes de Garcilópez y Pacheco: MONSALVO ANTÓN, 2009: 206-207.

64 En 1408, el linaje de San Benito de Salamanca tenía 55 inscritos y el de San Martín 42, en 1484 tenían 132 y 140, respectivamente. V. MONSALVO ANTÓN, 2013, 193.

65 ARAGÓN RUANO, (Madrid, 2012): 282. 
cargos, pronto lo lograrían a partir de la fusión, por vía de parentesco, con las familias de mercaderes y oficiales concejiles de las villas. En general, en las villas las familias de diferente origen supieron amoldarse a los nuevos tiempos y conseguir que sus descendientes se situasen en la burocracia y la administración, formándose también como intelectuales competitivos ${ }^{66}$.

\section{5.}

Por último, cabe preguntarse ¿qué nivel de conflictividad podía gestionar las ciudades antes de requerir la acción de la monarquía? La respuesta habría que relacionarla en la necesidad de paz que requería el funcionamiento de la vida económica y social de las ciudades y, por lo tanto, la necesaria búsqueda de soluciones para los conflictos puntuales o de larga duración. De las formas de violencia política en el ámbito urbano, los enfrentamientos de bandos o linajes fueron la manifestación más generalizada de lucha. Muy posiblemente esas disensiones ponían a prueba la propia cohesión de linajes, facciones y partidos, que a veces no podían evitar que apareciesen otras micro-facciones u otros micro-partidos hábiles en la solución de determinados conflictos. No obstante, en Castilla, ante cualquier conflicto no resuelto la vía más segura de atajarlo era pedir la intervención de la justicia regia y delegar en su acción la búsqueda de una solución satisfactoria. Es en este sentido mediador en el que cabría situar a la figura del corregidor, enviado regio que actuaba como oficial ajeno a la ciudad y que inicialmente acudía como enviado para asegurar la paz y hacer justicia, pero cuya presencia casi permanente se generalizó en la mayoría de las villas y ciudades del reino, a fines del siglo XV67. Ciertamente, la gobernabilidad urbana coincidía en sus objetivos con los de la monarquía para el reino: paz, sosiego, tranquilidad, concordia y unidad. Requisitos que Marsilio de Padua consideraba claves en la creación de la communitas perfecta $^{68}$.

La gestión de la violencia exigía conocer las causas de la misma ya que se consideraba violencia lícita ${ }^{69}$ la motivada por causas económicas. La violencia delincuencial que era la más mencionada y perseguida era también competencia de los vecinos que vigilaban para evitar altercados ${ }^{70}$. Es el caso de

66 ARAGÓN RUANO, (Madrid, 2012): 283.

67 GUERRERO NAVARRETE, (Alicante, 2000). ASENJO-GONZÁLEZ (Lisboa, 2015).

68 LÓPEZ GÓMEZ, 2008:20.

69 LÓPEZ GÓMEZ, 2006b: 23.

70 En Toledo, ante una llamada de socorro o ante la percepción de que se estaba cometiendo un delito, todos los vecinos que formaban la «comunidad» estaban obligados a acudir con sus armas para defender la paz: LÓPEZ GÓMEZ, (Madrid, 2006a): 66-67. 
las ciudades de Andalucía había también una violencia asociada a la proximidad de la frontera acuciada por la presencia amenazante de los musulmanes y también por la atracción que la frontera ejercía entre gentes violentas y proscritas. Al amparo de los privilegios de exención de culpas a delincuentes y homicianos, concedidos por los reyes, acudían gentes de distinta procedencia que debían permanecer en ella, durante un número de años, dedicados a las tareas más arriesgadas de la lucha ${ }^{71}$.

En cierto modo, la investigación de las formas del conflicto puede ayudar a clarificar la naturaleza de las relaciones entre los grupos sociales y los puntos de tensión entre centros de poder, a reconocer en los mecanismos en la base de las disputas y de sus recomposiciones un instrumento de legitimación social y política, en otras palabras, a contribuir a mitigar el aspecto genérico del estudio de la pugna por el poder en la Italia comunal. En las fuentes de edad comunal el lenguaje de las relaciones sociales y políticas aparece de hecho dominado por los conceptos de la amistad y la enemistad. De estos emerge explícitamente cómo las relaciones de solidaridad familiar y de facción definieron el sentimiento de pertenencia y los mecanismos de tutela de la identidad y del honor del individuo, también a través del conflicto. Esto ha llevado a investigar la dimensión política de los conflictos, la clarificación de sus prácticas como idiomas de la política, no sólo a la hora de constatar que la lucha por el poder se nutrió, en más de un caso, de conflictos de faida y enemistad, y que las facciones siguieron estrategias de conflicto claramente reconocibles, sino también en la evidencia documental de que la educación del ciudadano fue una educación en la vendetta y que a las prácticas sociales les correspondió la elaboración de una verdadera y propia cultura del conflicto.

Desde este enfoque, el sistema de los valores cívicos en las ciudades italianas se revela más complejo que la mera emersión lineal de virtudes republicanas. El análisis atento de la producción de los discursos morales y de las nociones de interés colectivo - como, en primer lugar, la paz, la concordia, el bien común y la justicia- muestra cómo fueron objeto de una constante reelaboración por parte de los actores políticos, plasmados en fines inmediatos, e invocados para legitimar los cambios en los núcleos de poder. Al mismo tiempo revela la consistencia esencialmente ideológica, desarrollada entre la búsqueda del consenso y la deslegitimación del adversario, en otros términos, como esta fue parte integrante de las estrategias del conflicto ${ }^{72}$. Por ejemplo, los valores negativos atribuidos a las violencias de los conflictos aparecen en gran medida como el resultado de elaboraciones conscientes, de demonizaciones del enemigo político, del que se hicieron protagonistas sobre todo los cronistas de la época del «popolo», fundando la visión negativa del compor-

71 CABRERA MUÑOZ, 1997: 1065.

72 ZORZI, 2010b. 
tamiento magnaticio y de las divisiones faccionarias de los grupos dirigentes, destinada a cristalizarse en el tiempo y a perpetuarse en parte incluso en la historiografía moderna.

Paces y treguas aparecen en las ciudades castellanas como las vías ordinarias para alcanzar soluciones a los conflictos, gracias al acuerdo de las partes. Pero, en el caso de las treguas, comprobamos que se trata de un término ambiguo, que no solo tiene consecuencias de aplazamiento sino que conlleva implicaciones integradoras, ya que las treguas en las villas del Cantábrico derivaban en posicionamientos de afinidades, y servían para lograr alineamientos a uno de los enfrentados con los que hacían la tregua, derivando así en soluciones que serían equivalentes a los bandos. Las treguas también asentaban alianzas entre los afines de un linaje para oponerse a otros linajes rivales asentados en el interior de la villa ${ }^{73}$. A las treguas quedaban adscritos los naturales del señorío que seguirían a su señor y se comprometían a respetar el acuerdo como «atreguados» ${ }^{74}$ y también las treguas constituían el armazón de las relaciones internobiliarias de Álava, Guipúzcoa y Vizcaya, construidas a partir de un sistema de relaciones clientelares y de parentesco que se estructuraban verticalmente y en las que confluían los parientes mayores del territorio ${ }^{75}$.

En las sociedades urbanas los diferentes grupos sociales actuaban como sistemas de contención y reconducción de la violencia en favor de opciones e intereses colectivos. La propia integración en linajes o bandos aseguraba líneas comunes de acción, al tiempo que imponía controles y reducción a las aspiraciones individuales y de cada grupo familiar ${ }^{76}$. Aunque las diferencias y disensiones internas podían degenerar en complicaciones, se resolvían en el seno de la propia estructura de encuadre y, como ocurría en el caso de Salamanca, se evitaban con la aplicación de criterios de reparto interno de oficios y cargos ${ }^{77}$.

Los pactos y acuerdos y las confederaciones de amistad eran la vía habitual para ampliar el grupo de afines y también para frenar la acción armada de las contiendas. Pero esas soluciones eran limitadas y precisaban ser renovadas periódicamente $^{78}$. Si bien, todas ellas contribuían a la gobernación de la ciudad y eran acordes con las necesidades y garantías del poder oligárquico, tales paces y acuerdos se ajustaban a modelos y rituales impregnados de términos y valores feudales, en las ciudades de predominio nobiliario, solían ponerse por

73 En Azpeitia, en 1435, los Emparán entraron en treguas con los Loyola frente a los Anchieta. La tregua se amplió e incluyó a otros cuatro vecinos de menor importancia, en 1441, DÍAZ DE DURANA y FERNÁNDEZ DE LARREA, 2013: 59-60.

74 DÍAZ DE DURANA y FERNÁNDEZ DE LARREA, 2013: 58.

75 DÍAZ DE DURANA y FERNÁNDEZ DE LARREA, 2013: 59.

76 MONSALVO ANTÓN, 2008: 176-177.

77 MONSALVO ANTÓN, 2008: 182-183.

78 Así, en Toledo, entre el 30 de enero de 1467 y el 24 de mayo de 1475, se hicieron siete paces en siete años: LÓPEZ GÓMEZ, (Madrid, 2006a): 80. 
escrito y se validaban con firmas y sellos ${ }^{79}$. El efecto de dichos pactos y treguas en la vida política de la ciudad podría modificar la cohesión interna de la misma, llegando a quebrarla, en algún caso, ya que generalmente sumaban voluntades por encima de las solidaridades linajísticas ${ }^{80}$. Pero la difusión de estas vías de encuadre y apaciaguamiento debió de ser muy grande y las consecuencias más inmediatas eran que quienes fueran capaces de mantener más atreguados en su bando desplegarían mayor influencia en su comunidad y en los gobiernos urbanos ${ }^{81}$. Eran, por tanto, vía común de solución de conflictos y servían para saldar responsabilidades y culpas, imponiendo una firmeza de estatus quo que no se podía cuestionar, tal y como nos consta a través de la documentación de los archivos regios ${ }^{82}$. Por medio de ellas se buscaba una salida que interesase a las partes, antes de que pudiese actuar un mediador ajeno. Ese sería el caso del juez de residencia (corregidor) del condado de Vizcaya, cuando recibió orden de no intervenir, a petición de Pedro de Avendaño y otros escuderos y personas de su linaje y solar de Urquijo, alegando que los conflictos de bando a bando ya se habían cerrado con un acuerdo de paz, se decía que los diez afectados, que pidieron la intervención de la justicia regia renunciaban a ello porque, de no hacerlo, todo el condado o la mayor parte de él se destruirían en pleitos, según las quemas y robos que habían acontecido. Añadía que ya se habían perdonado anteriormente por desmanes pasados y, si actuara la justicia regia recibirían mucho agravio. Esa petición de no intervención de la justicia real prueba la efectividad de los acuerdos, entre los que se incluyen las paces entre los bandos, y también el respeto y prioridad que se otorga al «bien común», entendido, en este caso, como la preservación de los intereses del acuerdo entre bandos, frente a la acción de la justicia regia ${ }^{83}$. Así, aunque las treguas y paces introducían disciplina y sosiego entre sus miembros, lo cierto era que la brevedad de duración de las treguas, paces y concordias cuestionaba la posibilidad de sentirse seguro a su amparo por mucho tiempo. Sin olvidar la implicación de los afectos y de la amistad/amor en la construcción de los bandos ${ }^{84}$.

79 ASENJO-GONZÁLEZ, 2008: 147.

80 MONSALVO ANTON, 2008, 201.

81 DÍAZ DE DURANA y FERNÁNDEZ DE LARREA, 2013, 61.

82 Así lo indica de la carta enviada desde el Consejo Real al Juez de residencia del Condado de Vizcaya para que entienda solamente en ciertos pleitos, por daños cometidos de bandos a bandos, ya que se perdonaron mutuamente todos los males cometidos en épocas anteriores; a petición de Martín Sánchez de Larraondo y otros nueve nombres más, vecinos del Condado: AGS/RGS legajo 1491-01, 42.

83 Sobre la cuestión de las implicaciones políticas del «bien común», consultar las interesantes reflexiones de GAMBERINI y ZORZI, 2011: 10-11.

${ }^{84}$ Ordenanzas contra bandos y parcialidades en la villa de Mondragón, señorío de Guipúzcoa, ante los enfrentamientos de los bandos de Gurraya y Bañez: AGS/RGS, legajo 1490- 
Tal y como hemos señalado, en la conflictividad urbana de Castilla, la intervención regia siempre se ha presentado como la clave para la contención de la acción violenta de los bandos. Un enfoque condicionado por la documentación que habría que compensar con el hecho de que, inicialmente, las solicitudes de acción de la justicia regia eran a instancia de parte y aprovechando su llamamiento de solicitud de justicia ${ }^{85}$. Además de que, frecuentemente, la figura pacificadora del corregidor se veía empequeñecida ante el poder de los bandos y necesitaba contar con su protección para tener alguna efectividad. Eso explica que los corregidores fuesen acusados de gobernar con parcialidad y de plegarse a los bandos, con una parcialidad en los enfrentamientos ya que no eran poderes completamente ajenos a los debates que debían de vigilar y contener ${ }^{86}$.

El recurso a las ordenanzas otorgadas o pactadas era otra de las vías posibles que regulaban, prohibían y obligaban a fin de contener la acción de los bandos. Se trataba de leyes de obligado cumplimiento, en las que se prohibía la creación de bandos y parcialidades y sus contenidos nos permiten señalar los puntos de efecto más utilizados por la autoridad emisora para contener las formaciones de bandos y sus consecuencias. Así se estipulaba en las ordenanzas de Mondragón (Guipúzcoa), ante los enfrentamientos de los bandos de Gurraya y Bañez ${ }^{87}$ y en ellas se prohíbe incluso las menciones a bandos y parcialidades, a fin de desarraigar y quitar de la memoria sus nombres y acabar con las cabsas de discordia ${ }^{88}$. No podían reunirse en bodas, misas nuevas y en velatorios, «a voz» de los dichos linajes, ni bandos y tampoco acudir a otras celebraciones conjuntas, no se permitía la fundación de cofradías ni acudir a pedir ayuda por llamamiento, ni juntar a otros caballeros, villas o ciudades. Las penas de castigo aplicables, serían: caer en la ira regia con pena de muerte, pérdida de la mitad de los bienes para la cámara real, o bien, quedarse como damnificador e enemigo de su patria e destruidor e quebrantador de pas e bien común ${ }^{89}$. A todo lo cual se añade el llamamiento para que cualquiera pudiese acusar ante el incumplimiento de lo dispuesto. Se daban por nulas las ligas y acuerdos hechas para favorecer al bando y con la insaculación se implantaba el modelo electivo para la elección anual de los oficios

$5,24, f^{0} 2 \mathrm{v}$. La importancia de esos afectos queda probada por la mención que se incluye en dichas ordenanzas, que tratan de prohibirlos, ya que expresamente dicen que «los eligieran $e$ nombraran syn aver respeto a vando ni a parentela ni a rruego ni amor ni a desamor»》

85 ASENJO-GONZÁLEZ, 2013.

86 AGS/Cámara de Castilla (Diversos) 43,48. (Sin fecha, fines del S.XV, principios del XVI). Memoriales de Francisco de Molina, vecino de la ciudad de Úbeda, sobre las parcialidades del corregidor en favor del linaje y bando de la Cueva y en contra de los de Molina.

87 AGS/Cámara de Castilla (Diversos) 43,48.

88 AGS/Cámara de Castilla (Diversos) 43,48.

89 AGS/Cámara de Castilla (Diversos) 43,48, f $1 \mathrm{v}$. 
concejiles. Finalmente, se optaba por dignificar y otorgar estatus a los elegidos para los oficios al otorgarles trato de «primados».

Pero las intervenciones regias y la legislación normativa en Castilla también trataban de contener la acción de los bandos mediante la prohibición de adhesiones de la comunidad urbana de vecinos a los conflictos. Así se hizo en la ciudad de Úbeda, con el fin de atajar la violencia generalizada, y se prohibió a la comunidad de dicho villa participar bajo amenaza de graves penas en caso de incumplimiento ${ }^{90}$. Fue también la intervención de la monarquía que impuso medidas de acuerdo en Salamanca en 1390-1394, 1440 y 1493, al mediar en las soluciones de reparto de poder entre los bandos o linajes de San Martín y San Benito ${ }^{91}$, al igual que en el País Vasco, donde apoyó a la Hermandad y facilitó a las ciudades que se impusieran a los parientes mayores y mantuviesen a raya a los banderizos ${ }^{92}$.

Un último elemento a valorar es el papel de la alta nobleza en Castilla, que estuvo presente en las ciudades y fue determinante en la conflictividad urbana conectada a las guerras y luchas extendidas por todo el reino. En esta cuestión cabe preguntarse si la nobleza es un elemento extraconcejil o bien se insertaba en el tejido social urbano y actuaba como parte del mismo ${ }^{93}$. Ciertamente, la inserción de la nobleza en la vida de las ciudades castellanas había sido tardía y desigual, ello nos obliga a distinguir entre ciudades con plena inserción de linajes nobles, que pugnan por el poder y se implican en la conflictividad que ellos dirigen y alimentan, mientras en otras habría una presencia más circunstancial y esporádica. Pero, en el siglo XV, las grandes ciudades castellanas contaban una presencia, más o menos prolongada, de familias nobles que trataban por todos los medios de afianzarse en la urbe, acceder a las fuentes de renta, adquirir tierra y otras propiedades y ocupar cargos y oficios en su gobierno. Ciudades de Andalucía, Toledo y Murcia tenían a grandes familias insertas en su vida política y en otras, como Salamanca, Segovia, Cuenca o Valladolid, participaban activamente en banderías y parcialidades, tratando de afianzarse. No obstante, se hacían fuertes en los períodos de inestabilidad política del reino, como fue el de la guerra civil de 1474-1476 y, durante esos años, también se operaban cambios que en ocasiones desubicaban las tradicionales rivalidades urbanas y daban opción a que surgieran posiciones de enfrentamiento desde otros sectores de la

90 AGS/RGS1477-12,5,53 - 1r.

91 MONSALVO ANTON, 2013, 188-189.

92 En 1449 Juan II ordenó que se rehicieran las Hermandades en los tres territorios y en 1457, Enrique IV realizó una ofensiva general contra los banderizos derribando un gran número de sus casas-torre y desterrando a varios de ellos a la frontera de Granada. En 1460 la mayoría de los parientes mayores desterrados también habían recibido el perdón real a cambio de jurar las ordenanzas de la Hermandad: DÍAZ DE DURANA, 1995, 46.

93 JARA FUENTE, 2001, 178. 
sociedad $^{94}$. Pero, lo cierto es que la nobleza no actuaba desde fuera de la ciudad sino desde dentro, logrando afinidades y entrando en la mecánica interna de exigencias para conseguir cargos y oficios ${ }^{95}$. Ciertamente, al considerar a la nobleza como un elemento exógeno a los intereses de la vida urbana se pierde la ocasión de conocer sus alicientes, ramificaciones clientelares, integración del comportamiento urbano y afinidades con los esquemas y valores de la oligarquía urbana, ya que cuando los nobles llegaban a la ciudad se plegaban a su funcionamiento social y acataban su jerarquía.

A su vez, en las ciudades italianas, la interacción de las instituciones con las prácticas del conflicto parece constante. No tanto para reprimirlas y prohibirlas cuanto para regularlas y contenerlas. La obligación del podestá de garantizar a la víctima el derecho de revancha, la definición normativa de las prácticas vengativas, la legitimación jurídica y política de los conflictos, son evidencias documentales que se alternaban con las treguas promovidas desde los órganos del común, a las comisiones de apaciguamiento, las dotaciones de sumas, los desagravios de pena, las interrupciones de los procesos judiciales, los solemnes rituales cívicos y religiosos de las pacificaciones.

Las reflexiones sobre los fundamentos violentos de la política parecen ofrecer claves interpretativas importantes para investigar la complejidad de las experiencias de sociedades como las urbanas italianas, en época comunal, y para captar la pluralidad de dimensiones que la política adoptó en las prácticas y en las representaciones del poder. En particular, estas pueden aportar algunos elementos para comprender mejor cómo una sociedad tan aparentemente conflictiva y violenta, lacerada por las divisiones y discordias, fue aun así capaz de durar en el tiempo y de practicar formas de convivencia política consensuales. Indagando en primer lugar sobre las formas y los instrumentos de expresión y de elaboración de la violencia, los modos y las culturas a través de las cuales los conflictos fueron practicados, gestionados y representados: para comprender la dimensión que podríamos llamar «constitucional» ${ }^{96}$.

Se trata por tanto de centrar la atención sobre un sistema de gestión del conflicto que, para satisfacer los intereses económicos y políticos, no atendió tan sólo a la ideología explícita de palabras de orden como «concordia», "paz», «securitas», «buen gobierno», etc., sino que adoptó lógicas internas al circuito de la violencia. Un sistema centrado sobre su gestión, pero orientado al consenso y a la integración social, consciente de que la experiencia individual y colec-

94 Enfrentamientos entre caballeros e hidalgos y el común hubo en la ciudad de Salamanca, tal y como refiere la Crónica incompleta de los Reyes Católicos: PUYOL, 1934, 305. El texto citado y por MONSALVO ANTÓN, 2013, 174, es interpretado como enfrentamiento entre los caballeros urbanos y los sectores populares.

95 MARTÍN ROMERA, 2012.

96 ZORZI, (Boloña, 2008); Aportaciones fundamentales en SCHIERA, (Boloña, 2006) y, releyendo a Otto Brunner, 1970. 
tiva, las relaciones sociales y políticas, se fundamentaban sobre la cultura de la amistad y la enemistad, sobre los valores del honor del individuo y del linaje. Y que era preciso aprender y educar para manejar esas relaciones. Gestionar la enemistad significaba por lo tanto prestar atención a las redes de amistad, cultivar el consilium, controlar y canalizar las emociones y las pasiones.

En otras palabras, la explicación no residía tan solo en la activación de una política de disciplinamiento y de nuevas reglas, y en la elaboración de una ideología del buen gobierno, sino que remitía a algunas razones del estar juntos también en las prácticas informales de la política. Es esta la razón de fondo que induce a evidenciar los límites de una interpretación centrada tan solo sobre la politics de las politicas formales, propagandísticas e institucionales. Las instituciones, en la acepción de públicas y colectivas, no reflejaron la esfera completa de la política. Hay distintos lugares donde se capta la actividad política, un área de «opacidad» constituida por las prácticas sociales legitimadas, y por tanto a su vez reconocibles como instituciones.

Bien visto, el reconocimiento de las relaciones sociales y políticas fundadas sobre la amistad y la enemistad era el soporte de la integración social y del mantenimiento «constitucional» del ordenamiento político comunal. Educar en la venganza y en la valoración de las oportunidades de revancha, favorecer las ocasiones de sedación y pacificación, significaba satisfacer a las partes, buscar el equilibrio social y por tanto la integración política. En otras palabras, el mantenimiento de larga duración de las instituciones comunales no estaba amenazado por la cultura de la vendetta. Las relaciones de amistad y de enemistad, bien controladas, a través de los mecanismos equilibradores de la vendetta, se configuraban como factores ordinarios de integración social y política.

El verdadero peligro para el orden comunal estaba representado por los conflictos —que podríamos llamar «asimétricos» ${ }^{97}$ - que no satisfacían a las partes, que no generaban consenso, que contemplaban la imposición de una pars sobre la otra. De ahí la obsesión en el discurso político comunal por las colligationes, por las partes que apuntaban a alcanzar la supremacía y, por tanto, el desequilibrio, por las facciones que se enfrentaban por el predominio absoluto, excluyendo, con el bando y con la magnatizzazione, a los enemigos políticos. Sobre todo el mecanismo de exclusión de los oficios y de la ciudadanía, junto con el dramático corolario de la destrucción de casas y bienes inmuebles, eran los principales factores de disgregación de la concordia cívica ${ }^{98}$.

97 Se utiliza aquí el término «asimétrico» como una función heurística, para indicar el caracter no equilibrado, no consensual y no legitimado, de algunas formas de conflicto, conscientes de que hoy en día está en voga entre los politólogos para indicar la acción política del terrorismo internacional.

98 La bibliografia sobre las facciones es vasta. Para época comunal cfr., por ejemplo, HYDE, 1972, HOJNACKI, 1973; VILLANI, 2000; MILANI, 2003 y 2011; REHBERG, 2004. 
Simplificando, se podría decir que la venganza y la faida eran simétricas y conducían al equilibrio, el conflicto entre las partes, el bando y la exclusión eran, por el contrario, asimétricos y conducían al desequilibrio. La vendetta es de hecho un conflicto consensual. Mario Sbriccoli, ha invitado a incluir entre los aspectos de la justicia «comunitaria local», destinada a resolver los conflictos entre vecinos, todas las prácticas como «vendette e ritorsioni, negoziati e accordi, transazioni e composizioni, mediazioni e paci private, patti, condiscendenze, rinunce, perdoni e remissioni». Según él, en la Italia comunal, la vendetta y la paz eran la justicia y eran por lo tanto compartidas y difundidas, mientras la pena y el proceso ex officio parecían «non corrispondere se non per tratti, e in speciali circostanze, all'idea di giustizia elaborata e introiettata dalle comunità». Sbriccoli, en definitiva, invita a tomar nota de que reflexionando sobre aquellas culturas y mentalidades, se debería quizás llamar justicia al primer tipo, y no al segundo: así se estaría mucho más cerca de la realidad. En sustancia, según Sbriccoli, la vendetta pertenecía a la justicia compartida y difundida, «la sola vera giustizia pensabile ed accettabile» ${ }^{99}$.

La vendetta pertenecía a la esfera de la justicia compartida y negociada, mientras que el bando no. La legitimación normativa y las ocasiones de mediación del conflicto conducían a no cruzar los límites del equilibrio entre las partes, ofreciendo reglas «equilibradas» para el juego político. Por esto el conflicto entre amigos y enemigos era parte de la constitución, incluso «material», del comune, pertenecía a la esfera de la política pura y dura, fundada sobre las relaciones de amistad y enemistad, sobre los valores del honor del individuo y de los linajes.

En el panorama de las sociedades de patronazgo y clientelismo, de las ciudades castellanas la presencia de linajes y la banderización, en el siglo XIII, supondría el tránsito de los modelos de justicia compartida y negociada, que se mencionaban en los fueros, hacia la creciente judicialización. Aunque no supuso la anulación de la justicia practicada que se mantenía conectada a las redes de poder y se imbricaba en muchos de los asuntos cotidianos. Pero en los conflictos que estallaban en la base social por enfrentamientos cotidianos parece que la gestión de esa violencia requería la acción mediadora de los grupos de poder, que se implicarían en la contención de esos estallidos de rabia, adelantándose habitualmente a la acción de la justicia. En cuanto a los tribunales regios, impartían justicia ante la solicitud de las partes y también reclamando atribuciones de gran calado, en los que se implicaba la paz del reino y el bien común, pero la insatisfacción del modelo de justicia regia existía y era frecuente para aquellos que o bien no se la podían pagar o consideraban inadecuados los códigos y los veredictos aplicados a la ofensa recibida.

\footnotetext{
99 SBRICCOLI, 2001.
} 


\section{BIBLIOGRAFÍA}

AA.VV., Pace e guerra nel basso medioevo, Spoleto 2004.

Actas. Bandos y querellas dinásticas en España al final de la Edad Media. Actas del Coloquio celebrado en la Biblioteca de París (15-16 mayo 1987), Madrid, Ministerio de Asuntos Exteriores, 1991.

Actes. Violence et contestation au Moyen Age. Actes du 114ème congrès national des Societés savantes, París, Edt. du C.T.H.S., 1989.

Atti. La giustizia nell'alto Medioevo (secoli IX-XI). Atti della 24a Settimana di studio (Spoleto, 11-17 aprile 1996), Spoleto, Fondazione CISAM, 1997.

Alfonso Antón, M. Isabel, Lenguaje y prácticas de negociar en la resolución de conflictos en la sociedad castellano-leonesa medieval, Barcelona, Institución Milá y Fontanals. Depto. de Estudios Medievales; Casa de Velázquez (Madrid), 2005.

Alfonso Antón, M. Isabel, «Vengeance, justice et lutte politique dans l'historiographie castillane du Moyen Âge», en Dominique Barthélemy, François Bougard y Regine Le Jan (eds.), La vengeance 400-1200, Rome, École française de Rome, 2006; 383-419.

Antelo Iglesias, Antonio, «La ciudad ideal según fray Francesc Eiximenis y Rodrigo Sánchez de Arévalo», En la España Medieval, 6 (Madrid, 1985): 19-50.

Aragón Ruano, Alvaro, «Linajes urbanos y parientes mayores en Guipúzcoa a fines de la Edad Media (1450-1520)», En la España Medieval, 35 (Madrid, 2012): 249-283.

Artifoni, Enrico, Retorica e organizzazione del linguaggio politico nel Duecento italiano, in Le forme della propaganda politica nel Due e nel Trecento, Paolo Cammarosano, Roma, Publications de l'École française de Rome, 1994; 157-182.

Artifoni, Enrico, «L'éloquence politique dans le cités communales (XIIIe siècle)», en Isabelle Heullant-Donat (ed.), Cultures italiennes (XIIe-XVe siècles), Paris, 2000; 269-296.

Artifoni, Enrico, «Prudenza del consigliare. L'educazione del cittadino nel «Liber consolationis et consilii» di Albertano da Brescia (1246)», en Carla Casagrande, Chiara Crisciani, Silvana Vecchio (eds.), «Consilium». Teorie e pratiche del consigliare nella cultura medievale, Firenze Edizione del Galuzzo, 2004; 195-216.

Artifoni, Enrico, «Repubblicanesimo comunale e democrazia moderna (in margine a Giovanni Villani, IV, 10: "Sapere guidare e reggere la nostra repubblica secondo la politica")», en Il governo delle città nell'Italia comunale: una prima forma di democrazia?, Atti della giornata di studi, Prato 12 ottobre 2005, Bollettino Roncioniano, 6 (Prato, 2006): 21-33.

Ascheri, Mario, Le città-Stato. Le radici del municipalismo e del repubblicanesimo italiani, Bologna, Il Mulino 2006a.

Ascheri, Mario, «Riconsiderare la civiltà comunale: con Maire Vigueur e oltre» en Il governo delle città nell'Italia comunale: una prima forma di democrazia?, Atti della giornata di studi, Prato 12 ottobre 2005, Bollettino Roncioniano, 6 (Prato, 2006b): 9-20. 
Asenjo-González, María, Segovia. La ciudad y su tierra a fines del Medievo, Segovia, Exma. Dip. Prov. Segovia y otros, 1986.

Asenjo-González, María, «La ciudad medieval castellana. Panorama historiográfico», Hispania, 50/2, 175 (Madrid, 1990):793-808.

Asenjo-González, María, «Las ciudades medievales castellanas. Balance y perspectivas de su desarrollo historiográfico (1990-2004)», En la España Medieval, 28 (Madrid, 2005): 415-453.

Asenjo-González, María, «La aristocratización política en Castilla y el proceso de participación urbana (1252-1520)», en José Manuel Nieto Soria (coord.), La monarquía como conflicto en la Corona castellano-leonesa (1250-1450), Madrid, Silex, 2006; 133-196.

Asenjo-González, María, «Concordia, pactos y acuerdos en la sociedad política urbana de la Castilla bajomedieval», en François Foronda, F. y Ana Isabel Carrasco Manchado (eds.), El contrato político en Europa Occidental: la cadena contractual en Castilla, Madrid, Dykinson, 2008; 125-158.

Asenjo-González, María, «Acerca de los linajes urbanos y su conflictividad en las ciudades castellanas a fines de la Edad Media», Clío \& Crimen, 6 (Vitoria, 2009a): 52-84.

Asenjo-González, María, «La aportación del sistema urbano a la gobernabilidad del reino de Castilla durante el reinado de los Reyes Católicos (1474-1504)», Anuario de Estudios Medievales, 39-1 (Barcelona, 2009b): 307-328.

Asenjo-González, María, «La venganza en el ámbito de las ciudades castellanas y su transformación en la Baja Edad Media», en Claude Gauvard y Andrea Zorzi (eds.), La vendetta in Europa, 1200-1800; La vengeance en Europe, XIIe-XVIIIe siècle, París, Publications de la Sorbonne, 2015, 227-247.

Asenjo-González, María, «Linaje, bandos y confictos en las ciudades castellanas. Un estado de la cuestión», en María Asenjo-González y Andrea Zorzi (coords.), Factions, Lineages and Conflicts in European Cities in the Late Middle Ages. Models and Analysis from Hispanic and Italian Areas, Florence University Press, Firenze, 2013; 1-21 (en prensa).

Asenjo-González, María, «Preparar la paz y prevenir la guerra en las ciudades medievales», en Ana Arranz Guzman, Mª Pilar Rábade Obradó y Óscar Villarroel González (coords.), Guerra y paz en la Edad Media, Madrid, Silex, 2013; 109-140.

Asenjo González, María, «Fundación pacificadora y judicial de los corregidores en las villas y ciudades castellanas, a fines de la Edad Media» Medievalista on line, 18, $\mathrm{n}^{\mathrm{o}}$. julho-dezembro (Lisboa, 2015): 1-28. (http://www2.fcsh.unl.pt/iem/medievalista/ MEDIEVALISTA18/gonzalez1804.html Julio 2015)

Bonachía Hernando, Juan Antonio, El concejo de Burgos en la Baja Edad Media (1345-1426), Valladolid, Univ. de Valladolid, 1978.

Bonachía Hernando, Juan Antonio, «Crisis municipal, violencia y oligarquías en Burgos a comienzos del siglo XV», en Manuel González Jiménez (coord.), La Península Ibérica en la era de los descubrimientos, Sevilla, Junta de Andalucía, 1997; 1081-1095. 
Barthélemy, Dominique; Bougard, François y Le Jan, Regine (coords.), La vengeance. 400-1200, Rome Collection de l'École française de Rome, 357, 2006.

Bériou, Nicole, «Le sermon sur la paix prononcé devant le Conseil communal de Pise par Federico Visconti en 1267», en Rosa Maria Dessì (ed.), Prêcher la paix, et discipliner la société: Italie, France, Angleterre (XIII ${ }^{e}-X V^{e}$ siècle), Brepols, Turnhout, 2005: 357-366.

Blockmans, Wim Pieter, Een middeleeuwse vendetta: Gent 1300, De Haan, Houten, 1987.

Blockmans, Wim Pieter, «Vete, partijstrijd en staatsmacht», en Jannis Willem Marsilje (ed.), Bloedwraak, partijstrijd en pacificatie in laat-middeleeuws Holland, Hilversum, Neth., 1990; 9-33.

Bock, Gisela, Skinner, Quentin y Viroli, Maurizio (eds.), Machiavelli and republicanism, Cambridge, Cambridge University Press, 1990.

Boone, Marc «Urban Space and Political Conflict in Late Medieval Flanders», The Journal of Interdisciplinary History, 32/ 4 (Massachusetts, 2002): 621-640.

Bossy, John (ed.), Disputes and settlements. Law and human relations in the West, Cambridge, Cambridge University Press, 1983.

Boucheron, Patrice, Les villes d'Italie (vers 1150-vers 1340), Paris, Belin, 2004

Braake, S.T.: «Parties and factions in the late middle ages: the case of the Hoeken and Kabeljauwen in The Hague (1483-1515)», Journal of Medieval History, 35/1 (Cambridge, 2009): 97-111.

Brown, Warren C. y Górecki, Piotr (eds.), Conflict in medieval Europe. Changing perspectives on society and culture, Aldershot, Ashgate, 2003.

Buylaert, Frederic, «Familiekwesties. De beheersing van vetes en private conflicten in de elite van laatmiddeleeuws Gent» en Tijdschrift voor Stadsgeschiedenis, 2 (Amsterdam, 2007): 1-19.

Cabrera Muñoz, Emilio, «Violencia urbana y crisis política en Andalucía durante el siglo XV», Violencia y conflictividad en la sociedad de la España bajomedieval, Zaragoza, Universidad de Zaragoza, 1995; 5-25.

Cabrera Muñoz, Emilio, «Sobre la violencia en Andalucía durante el siglo XV», en Manuel González Jiménez (coord.), La Península Ibérica en la era de los descubrimientos, Sevilla, Junta de Andalucía, 1997; 1063-1079.

Carmona Ruiz, $\mathrm{M}^{\mathrm{a}}$ Antonia, «Lucha de bandos en Baeza» en Manuel González Jiménez (coord.), La península Ibérica en la era de los descubrimientos, Sevilla, Junta de Andalucía, 1998; 1301-1307.

Carroll, Stuart, «The peace in the feud in sixteenth- and seventeenth- century France», Past and Present, 178 (Oxford, 2003); 74-115.

Carroll, Stuart, Blood and violence in early modern France, Oxford, Oxford University Press, 2006.

Cavina, Marco (ed.), Duelli, faide e rappacificazioni: elaborazioni concettuali, esperienze storiche, Milano, Giuffrè, 2001. 
Cervera Vera, Luis, Francisco de Eiximenis y su sociedad urbana ideal, Madrid, Swan, 1989.

Chiffoleau, Jacques, Gauvard, Claude y Zorzi, Andrea (eds.), Pratique sociales et politiques judiciaires dans les villes de l'Occident à la fin du Moyen Age, Roma, École française de Rome, 2007.

Chojnacki, Stanley, «In search of the Venetian patriciate: families and factions in the fourteenth century», en John Rigby Hale (ed.), Renaissance Venice, London, New York Univ. Press, 1973; 47-90.

Connell, William John, La città dei crucci. Fazioni e clientele in uno stato repubblicano del '400, Firenze, Nuova Toscana Editrice, 2000.

Crouzet-Pavan, Élisabeth, Enfers et paradis. L'Italie de Dante et de Giotto, Paris, Bibliothèque Albin Michel, 2001.

Della Misericordia, Massimo, La disciplina contrattata. Vescovi e vassalli tra Como e le Alpi nel tardo Medioevo, Milano, Unicopli, 2000.

Dessì, Rosa Maria, «Pratiques de la parole de paix dans l'histoire de l'Italie urbaine», en Rosa Maria Dessì, (ed.) Prêcher la paix, et discipliner la société: Italie, France, Angleterre (XIII $-X V^{e}$ siècle), Brepols, Turnhout, 2005: 245-278.

Díaz de Durana Ortiz de Urbina, Juan Ramón, «Violencia, disentimiento y conflicto en la sociedad vasca durante la Baja Edad Media: la lucha de bandos, estado de la cuestión de un problema historiográfico», Aragón en la Edad Media: sesiones de trabajo, Zaragoza, Universidad de Zaragoza, 1995; 27-58.

Díaz de Durana Ortiz de Urbina, Juan Ramón, «Linajes y bandos en el País Vasco durante los siglos XIV y XV», en José Ignacio de la Iglesia Duarte (coord.), La Familia en la Edad Media: XI Semana de Estudios Medievales, Nájera, del 31 de julio al 4 de agosto de 2000, Logroño, 2001; 253-284.

Díaz de Durana Ortiz de Urbina, Juan Ramón y Fernández de Larrea, Jon Andoni, «Las villas cantábricas bajo el yugo de la nobleza. Consecuencias sobre los gobiernos urbanos durante la época Trastámara», en José Ma Monsalvo Antón (ed.) Sociedades urbanas y culturas politicas en la Baja Edad Media castellana, Salamanca, Ediciones Universidad, 2013; 49-70.

Frenz, Barbara, «Paix, honneur et discipline. Quelques remarques sur l'incrimination d'insultes et d'actes de violence dans les villes médiévales», en Jacqueline Hoareau-Dodinau y Pascal Texier (eds.), Pouvoir, justice et société: actes des XIX èmes Journées d'Histoire du Droit, 9 - 11 juin 1999, Limoges, PULIM, 2000; 65-79.

Frenz, Barbara, Frieden, Rechtsbruch und Sanktion in deutschen Städten vor 1300: Mit einer tabellarischen Quellenübersicht nach Delikten und Deliktgruppen, Köln, Böhlau Verlag, 2003.

Gamberini, Andrea y Zorzi, Andrea, «Introduction», en Andrea Gamberini, JeanPhilippe Genet y Andrea Zorzi (eds.), The languages of political society: Western Europe, 14th-17th centuries, Roma, Viella, 2011; 9-16. 
García Fernández, Ernesto, «Teoría y praxis política en el País Vasco a fines de la Edad Media: los gobiernos urbanos y los vecinos de la tierra», en José $\mathrm{M}^{\mathrm{a}}$ Monsalvo Antón (ed.), Sociedades urbanas y culturas políticas en la Baja Edad Media castellana, Salamanca, Universidad de Salamanca, 2013; 71-121.

Gauvard, Claude, Violence et ordre public au Moyen Age París, Picard, 2005.

Gentile, Marco (ed.), Guelfi e ghibellini nell'Italia del Rinascimento, Roma, Viella, 2005.

Gluckman, Max, «The peace in the feud», Past and present, 8 (Oxford, 1955):1-14.

Gonthier, Nicole, Cris de haine et rites d'unité: la violence dans les villes, XIIIe-XVIe siècle. s.l., Brepols, 1992.

Gonzalez Jimenez, M.: Alfonso X el Sabio. Barcelona, Ariel, 2004.

Guerrero Navarrete, Yolanda, «Orden público y corregidor en Burgos (siglo XV)», Anales de la Universidad de Alicante. Historia medieval, 13 (Alicante, 2000): 59102.

Head, Thomas F. y Landes, Richard (eds.), The Peace of God. Social Violence and Religious Response in France around the year 1000, Ithaca, Cornell University Press, 1992.

Heers, Jacques, Le clan familial au moyen âge. Étude sur les structures politiques et sociales des milieux urbains, Paris, Presses Universitaires de France, 1974.

Heers, Jacques, Parties and political life in the medieval West, Amsterdam-New York-Oxford, North-Holland Publishing, 1977.

Herranz Torres, Alberto, «La lucha de bandos en la Úbeda renacentista», en Pedro Porras Arboledas (coord.), Úbeda durante el primer Renacimiento la vida privada (1459-1525), Madrid, Dyckinson, 2010; 27-94.

Hyde, John Kenneth, "Contemporary views on faction and civil strife in thirteenthand fourteenth-century Italy», in Lauro Martines (ed.) Violence and civil disorder in Italian cities; 273-307.

Iannella, Cecilia, «La paix dans la prédication du dominicain Giordano de Pise (vers 1260-1310)» en Rosa Maria Dessì (ed.), Prêcher la paix, et discipliner la société: Italie, France, Angleterre (XIII ${ }^{e}-V^{e}$ siècle), Brepols, Turnhout, 2005: 367-382.

Klapisch-Zuber, Christian, Retour à la cité. Les magnats de Florence, 1340-1440, Paris, Editions Ecole des Hautes Etudes en Sciences Sociales, 2006.

Kuehn, Thomas J., «Law and arbitration in Renaissance Florence», Thomas J. Kuehn (ed.), Law, Family, and Women. Toward a Legal Anthropology of Renaissance Italy, Chicago, University of Chicago Press, 1991.

Ladero Quesada, Miguel Angel, «Algunas reflexiones sobre los orígenes del "Estado Moderno" en Europa (siglos XIII-XVIII)», La península Ibérica en la era de los descubrimientos, Manuel González Jiménez (ed.) Sevilla, Junta de Andalucía, 1997; 483-497.

Lansing, Carol, The Florentine Magnates. Lineage and Faction in a Medieval Comune. New Yersey, Princeton University Press, 1991. 
López Gómez, Óscar, «Pas e sosiego. Un argumento de acción política en la Castilla bajomedieval», Medievalismo. Boletín de la Sociedad Española de Estudios Medievales, 16 (Madrid, 2006a); 41-71.

López Gómez, Óscar, La sociedad amenazada. Crimen, delincuencia y poder en Toledo a fines del siglo XV, Toledo, 2006b.

López Gómez, Óscar, Los Reyes Católicos y la pacificación de Toledo, Madrid, Castellum, 2008.

Maire-Vigueur, Jean-Claude, Cavaliers et Citoyens. Guerre, conflicts et socièté dans l'Italie communale, XII $-X I I I^{e}$ siècles, Paris, Editions de l'Ëcole des Hautes Études en Sciences sociales, 2003.

Martín Cea, Juan Carlos y Bonachía Hernando, Juan Antonio, «Oligarquías y poderes concejiles en la Castilla bajomedieval: balance y perspectivas», Revista d'Historia Medieval, 9 (Valencia, 1998): 17-40.

Martín Romera, $\mathrm{M}^{\mathrm{a}}$ Ángeles, Las redes sociales de la oligarquía de la villa de Valladolid, (1450-1520), Valladolid, Universidad de Valladolid, 2015 (en prensa).

Martín Romera, Ma Ángeles, «Bandos, violencia y alteración de la paz pública en las ciudades bajomedievales: el caso de Valladolid», en Ana Arranz Guzmán, Ma Pilar Rábade Obradó, y Óscar Villarroel González (coords.), Guerra y paz en la Edad Media, Madrid, Silex, 2013; 163-187.

Martines, Lauro, «Political conflict in the Italian city states», Government and opposition. A quarterly of comparative politics, III, (London, 1968): 69-91.

Martines, Lauro (ed), Violence and civil disorder in Italian cities, 1200-1500, Berkeley, University of California Press, 1972.

Martínez Díez, Gonzalo, Fernando III (1217-1252), Palencia, La Olmeda, 1993.

Mackay, Angus, Anatomía de una revuelta urbana. Alcaraz en 1458, Albacete, Instituto de Estudios Albacetenses, 1985.

Menant, François, Les villes italiennes, XII -XIV siècle. Enjeux historiographiques, méthodologie, bibliographie commentée, Paris, Armand Colin, 2004.

Menant, François, L'Italie des communes (1100 - 1350), Paris, Belin, 2005.

Menjot, Denis, «Hidalguía et caballería à Murcie: contours sociaux d'une aristocratie urbaine du XIIIème au XIVème siècle», Les sociétés urbaines en France Méridionale et la Péninsule Iberique au Moyen Age, París, C.N.R.S., 1991; 219-228.

Menzinger, Sara «Forme di organizzazione giudiziaria delle città comunali italiane nei secoli XII e XIII: l'uso dell'arbitrato nei governi consolari e podestarili», en Franz-Josef Arlinghaus (ed.), Praxis der Gerichtsbarkeit in europäischen Städten des Spätmittelalters, Frankfurt a. M., Vittorio Klostermann, 2006; 113-134.

Michetti, Raimondo, «François d'Assise et la paix révélée. Réflexions sur le mythe du pacifisme franciscain et sur la prédication de paix dans la société communale du XIIIe siècle» en Dessì, Rosa Maria (ed.), Prêcher la paix, et discipliner la société: Italie, France, Angleterre (XIII'-XV' siècle), Brepols, Turnhout, 2005: 279-312. 
Milani, Giuliano, L'esclusione dal comune. Conflitti e bandi politici a Bologna e in altre città italiane tra XII e XIV secolo, Roma, 2003.

Milani, Giuliano, I comuni italiani: secoli XII-XIV, Roma-Bari, Laterza, 2005.

Milani, Giuliano, «Partecipare al comune: inclusione, esclusione, democrazia», en Il governo delle città nell'Italia comunale: una prima forma di democrazia?, Atti della giornata di studi, Prato 12 ottobre 2005, Bollettino roncioniano, 6 (Prato, 2006): 35-49.

Milani, Giuliano, «Le ragioni dell'esclusione: definire il nemico pubblico nei comuni italiani», en Fabio Di Giannatale (ed.), Escludere per governare: l'esilio politico fra Medioevo e Risorgimento, Firenze, Le Monnier, 2011; 17-31.

Monsalvo Antón, José $\mathrm{M}^{\mathrm{a}}$, «En torno a la cultura contractual de las élites urbanas: pactos y compromisos políticos (linajes y bandos de Salamanca, Ciudad Rodrigo y Alba de Tormes)», en François Foronda y Ana Isabel Carrasco Manchado (coords.), El contrato político en la Corona de Castilla: cultura y sociedad politicas entre los siglos X al XVI, Madrid, Dickinson, 2008; 159-209.

Monsalvo Antón, José $\mathrm{M}^{\mathrm{a}}$, «Luchas de bandos en Ciudad Rodrigo durante la época Trastámara » en Pascual Martínez Sopena y $\mathrm{M}^{\mathrm{a}}$ Isabel Val Valdivieso (coords.) Castilla en el mundo feudal. Homenaje al profesor Julio Valdeón, Valladolid, Junta de Castilla y León, 2009; 201-214.

Monsalvo Antón, José Ma , «Torres, tierras, linajes. Mentalidad social de los caballeros urbanos y de la élite dirigente en Salamanca medieval (siglos XIII-XV)», en José Ma Monsalvo Antón (coord.), Sociedades urbanas y culturas políticas en la Baja Edad Media castellana, Salamanca, Universidad de Salamanca, 2013; 165-230.

Mundy, John Hine, In praise of Italy: the Italian republics, «Speculum», 64 (Massachusetts, 1989): 815-834.

Muir, Edward, Mad blood stirring. Vendetta and Factions in Friuli during the Renaissance, Baltimore, Johns Hopkins University Press, 1993.

Netterström, Jeppe Büchert y Poulsen, Bjørn. (eds), Feud in Medieval and Early Modern Europe, Aarhus, Aarhus University Press, 2007.

Pocock, John G.A., The Machiavellian Moment. Florentine Political Thought and the Atlantic Republican Tradition, Princeton, Princeton University Press, 1975.

Raggio, Osvaldo, Faide e parentele. Lo stato genovese visto dalla Fontanabuona, Torino, Einaudi, 1990.

Rehberg, Andreas, «Clientele e fazioni nell'azione politica di Cola di Rienzo», en Andreas Rehberg, Anna Modigliani, Cola di Rienzo e il comune di Roma, Roma, 2004.

Rossi, Maria Clara. «Polisemia di un concetto: la pace nel basso medioevo. Note di lettura, in La pace fra realtà e utopia», Quaderni di Storia Religiosa, 12 (Verona, 2005): 9-46.

Rovigo, Vito, «Le paci private: motivazioni religiose nelle fonti veronesi del Quattrocento», en La pace fra realtà e utopia, Quaderni di Storia Religiosa, 12 (Verona, 2005): 201-233. 
Rucquoi, Adeline, «Pouvoir royal et oligarchies urbaines d'Alfonso X à Fernando IV de Castille», en Adeline Rucquoi (coord.), Génesis medieval del Estado Moderno: Castilla y Navarra (1250-1370) Valladolid, Ámbito, 1987; 173-192.

Rucquoi, Adeline (coord.), Genèse médiévale de l'Espagne moderne. Du refus à la révolte: les résistances. Nice, Public. de la Fac. de Nice, 1991.

Sabaté, Flocel, «Les factions dans la vie urbaine de la Catalogne du XIV ${ }^{\mathrm{e}}$ siècle», en Phillippe Sénac (ed.), Histoire et archéologie des terres catalanes au moyen âge, Perpignan, Presses Universitaires de Perpignan 1995 ; 339-365.

Sabaté, Flocel, «Els bàndols com a solidaritat en la societat urbana baixmedieval», Afers. Fulls de recerca i pensament, 30 (Valencia, 1998): 457-472.

Sánchez de Arévalo, Rodrigo, «Summa de la política», en Manuel Penna (ed.), Prosistas castellanos del siglo XV, Madrid, Ediciones Atlas, 1959; 247-309.

Sbriccoli, Mario, «Giustizia negoziata, giustizia egemonica. Riflessioni su una nuova fase degli studi di storia della giustizia criminale», en Marco Bellabarba, Gerd Schwerhoff y Andrea Zorzi (coord.), Criminalità e giustizia in Germania e in Italia. Pratiche giudiziarie e linguaggi giuridici tra tardo medioevo ed età moderna, Bologna, Bologna-Berlin, il Mulino-Duncker \& Humblot, 2001; 349-350.

Schiera, Pierangelo, «Il Buongoverno "melancolico" di Ambrogio Lorenzetti e la "costituzionale faziosità" della città», Scienza e politica. Per una storia delle dottrine politiche, 34 (Boloña, 2006): 93-108.

Schiera, Pierangelo, «Il concetto moderno di costituzione e la storia costituzionale del medioevo», Per una nuova storia costituzionale e sociale, Otto Brunner, Milán, Vita e Pensiero, 1970; 1-20.

Sensi, Mario, «Le paci private nella predicazione, nelle immagini di propaganda e nella prassi fra Tre e Quattrocento», en La pace fra realtà e utopia, Quaderni di storia religiosa, 12 (Verona, 2005): 159-200.

Skinner, Quentin, The foundations of modern political thought. I. The Renaissance, Cambridge, Cambridge University Press, 1978.

Skinner, Quentin y Van Gelderen, Martin (eds.), Republicanism. A shared European heritage, Cambridge, Cambridge University Press, 2002.

Simonde de Sismondi, Jean-Charles-Léonard, Storia delle Repubbliche italiane, Torino, Bollati Boringhieri, 1996.

Solórzano Telechea, Jesús Ángel, «Violencia y conflictividad política en el siglo XV: el delito al servicio de la élite en las Cuatro Villas de la Costa de la Mar», Anuario de Estudios Medievales, 35 (Barcelona, 2005); 159-184.

Smail, Daniel Lord, «Common violence. Vengeance and inquisition in fourteenthcentury Marseille», Past and Present, 151 (Oxford, 1996): 28-59.

Smail, Daniel Lord, The Consumption of Justice. Emotions, Publicity, and Legal Culture in Marseille, 1264-1423, Ithaca, Cornell University Press, 2003.

Soria Mesa, Enrique, La nobleza en la España moderna. Cambio y continuidad. Madrid, Marcial Pons, 2007. 
Tabacco, Giovanni, «Recensione critica», Studi medievali, 3/17 (Spoleto, 1976):219224.

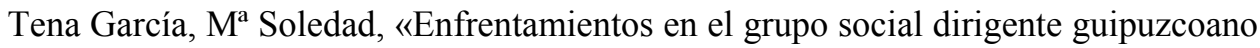
durante el siglo XV». Studia Historica, 8 (Salamanca, 1990);139-158.

Valdeon Baruque, Julio, «Resistencia y estado moderno en Castilla 1350-1521», en Manuel González Jiménez (ed.) La Península Ibérica en la era de los descubrimientos, Sevilla, Junta de Andalucía, 1997; 499-514.

Vallerani, Massimo, «Pace e processo nel sistema giudiziario del comune di Perugia», Quaderni Storici, 101 (Roma, 1999): 315-354.

Wickham, Chris, «Ecclesiastical dispute and lay community: Figline Valdarno in the twelfth century», Mélanges de l'École française de Rome. Moyen âge, temps modernes, 108 (Roma, 1996): 7-93.

Wickham, Chris, Legge, pratiche e conflitti. La risoluzione delle dispute nella Toscana del XII secolo, Roma, Viella libreria editrice, 2000.

Villani, Virginio, «Lotte di fazione, governi di popolo e politica antimagnatizia nei comuni marchigiani dei secoli XIII e XIV», en Istituzioni e società nelle Marche (secc. XIV-XV). Atti del convegno Ancona-Camerino-Ancona, 1-2-3 ottobre 1998, Ancona, 2000; 7-134.

Zorzi, Andrea, «La cultura de la vendetta nel conflitto politico in età comunale» en Delle Donne, R. y Andrea Zorzi (coord.), Le storie e la memoria: in onore di Arnold Esch, Florencia, 2002; 135-170.

Zorzi, Andrea, "“Fracta est civitas magna in tres partes"», Conflitto e costituzione nell'Italia comunale. Scienza \& Politica, 39 (Boloña, 2008): 61-86.

Zorzi, Andrea, «I conflitti nell'Italia comunale. Riflessioni sullo stato degli studi e sulle prospettive di ricerca», en Andrea Zorzi (ed.), Conflitti, paci e vendette nell'Italia comunale, Firenze, Firenze University Press, 2009.

Zorzi, Andrea, «Pace e conflitti nelle città comunali italiane», en Flocel Sabaté (coord.), Idees de pau a l'edat mitjana, Lleida, Pagès 2010a; 265-301.

Zorzi, Andrea, «Bien commun et conflits politiques dans l'Italie communale», en Elodie Lecuppre-Desjardin, Anne-Laure Van Bruaene (eds.), «De Bono Communi» The Discourse and Practice of the Common Good in the European City (13th16th c.), Turnhout, Brepols, 2010b; 267-290.

Recibido: 21/10/2013

Aceptado: 08/09/2014 